\title{
Hunter-Gatherer Adaptations in Madurai Region, Tamil Nadu, India: From c. 10,000 B.P. to c. A.D. 500
}

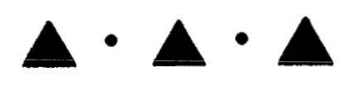

\section{SELVAKUMAR}

The Pleistocene-Holocene transition witnessed several significant modifications in human adaptation patterns, including a shift to microlithic implements, small-game hunting and gathering, and a highly mobile lifestyle in several parts of the world. The term Mesolithic is widely used to denote this cultural period, which succeeded the Palaeolithic and preceded the emergence of an agropastoral way of life (the Neolithic). The transformation from hunting-gathering (the Mesolithic) to agropastoralism (the Neolithic) that took place in certain territories during the early Holocene was not a universal phenomenon, but a localized one. It is a gradual process that has been going on for several millennia worldwide.

Evidence for Mesolithic and post-Mesolithic hunter-gatherers occurs extensively in different parts of world including South Asia. In India, from the 1880s when A.C.L. Carlleyle discovered the first microliths in the Vindhyan hills (Misra 1965:58), several microlithic sites of the Mesolithic period have been brought to light (Allchin and Allchin 1983:62-96; Misra 1965, 1989). The survival of microlith-using groups, primarily subsisting on hunting and gathering and their interactions with agropastoral communities of the protohistoric and historical periods have been recognized in archaeological context in several areas like Rajasthan, Gujarat, Central India, and Andhra Pradesh (Allchin 1977; Allchin and Allchin 1974; Hooja 1988; Jacobson 1970, 1975; Misra 1973, 1976; Murty 1989; Stiles 1993).

Recent investigations in the hitherto archaeologically unexplored region of southern Tamil Nadu have exposed a wide spectrum of evidence for human occupation during the Mesolithic and the Iron Age-Early Historic periods (Selvakumar 1996, 1997, 2000). Based on these findings, this paper discusses the adaptation patterns of the hunter-gatherer groups, which occupied the Gundar Basin (Madurai district of Tamil Nadu) from the early Holocene to the end of the Early Historic period, i.e., up to c. A.D. 500.

The term Iron Age here refers to the period that falls between the introduction

V. Selvakumar is a post-doctoral fellow in the Department of Archaeology, Deccan College, Pune, India.

Asian Perspectives, Vol. 41, No. 1 (C) 2002 by University of Hawai ${ }^{i}$ Press. 
of iron and the beginning of the Early Historic period. In South India, the Iron Age is placed within a tentative time bracket of c. 1000 to 300 B.C., and the Early Historic period, between c. 300 B.C. and C. A.D. 500 (Allchin and Allchin 1983).

\section{THE STUDY AREA: ENVIRONMENTAL BACKGROUND}

This study focuses on an area of about $400 \mathrm{~km}^{2}$ (between $77^{\circ} 35^{\prime}$ to $77^{\circ} 55^{\prime} \mathrm{E}$ and $9^{\circ} 40^{\prime}$ to $9^{\circ} 55^{\prime} \mathrm{N}$ ), in the upper Gundar Basin, which occupies the western part of the Madurai district of Tamil Nadu (Figs. 1-2). The Varushanad-Andipatti hills, an offshoot of the Western Ghats, and its branches, the Chaturagiri and the Kudiraimalai (or the Vasimalai), enclose the area respectively, on the western, southern, and northern sides. The basin has a gneissic base intruded by Charnockite and Khondalite groups of rocks (HBG 1976) and is drained by the seasonal river Gundar and its tributaries, the Varattar and the Uppar. It can be divided into two physiographic zones, the plains with a varying altitude of 150 to $250 \mathrm{~m}$ above mean sea level (hereafter, AMSL) scattered with a few isolated hillocks, and the hilly tracts, which cover the area above $250 \mathrm{~m}$ AMSL. The climate of the area falls between semi-arid and sub-humid types with an annual average precipitation of around $900 \mathrm{~mm}$. Most of the rainfall occurs during the northeast monsoon season (October to December) and a small amount in summer (April to May). The ombrothermic diagram for the meteorological station at Madurai, situated $50 \mathrm{~km}$ northeast of the basin, shows two dry seasons separated by wet seasons (Gaussen et al. 1964).

The plain area of the basin is inhabited by agropastoral communities and is largely under cultivation. It has no forest cover and hence today there are very few wild animals except hare, jackal, and fox. The hilly tract has mostly denuded scrub forest and a few pockets of dry deciduous forest, one of which harbors a small settlement of Paliyans, a food-gathering group (P. M. Gardner 1972, 1988). It also has numerous wild animals including different deer species, elephants, and bison.

\section{PREVIOUS WORK AND OBJECTIVES OF THE PRESENT RESEARCH}

The southern part of Tamil Nadu has not been subjected to intensive archaeological research because of its marginalized location and the lack of any significant findings in the sporadic surveys conducted before the 1980s. Previous research on the prehistoric front concentrated on the microlith-bearing Teris (red sand-dune formations) situated along the southeast coast of India (Aiyappan 1944; Foote 1883, 1916; R.A.M. Gardner 1986, 1995; R.A.M. Gardner and Martingell 1990; Zeuner and Allchin 1956).

Systematic archaeological research commenced in this basin mainly in the late 1950s when Raman (1970) carried out surface surveys. Before the 1950s, R. B. Foote came across a few sites with lithic artifacts in the area, which lie to the east and southeast of the basin, during his geological surveys in the late nineteenth century (Foote 1883, 1916). However, Raman's survey is the first problemoriented investigation to be conducted in southern Tamil Nadu (Indian Archaeology: A Review 1957-1958:38, 1958-1959:31-32, 1960-1961:18-19; Raman $1970)$. His surveys undertaken with the objective of reconstructing the culture- 
history of the region, exposed the presence of the Mesolithic and the Iron AgeEarly Historic (or the Megalithic) periods and the absence of the Neolithic and the Chalcolithic periods in the Gundar Basin. His studies also revealed two sites, which he ascribed to the Middle Palaeolithic (Series II).

Despite Raman's initial work, which established a preliminary cultural sequence, several aspects, especially the chronology and subsistence and settlement patterns of the ancient cultures of the Gundar Basin in particular and southern Tamil Nadu in general, have been largely ignored. Against this background, the research under discussion was initiated. Furthermore, the studies conducted in the 1980s and 1990s on the Teri sites (R.A.M. Gardner 1986, 1995; R.A.M. Gardner and Martingell 1990; Zeuner and Allchin 1956), as well as the recent research in Sri Lanka (Deraniyagala 1992:118), also necessitated investigations in the interior southern Tami Nadu for fresh evidence.

\section{SURVEY METHODOLOGY}

The investigations involved intensive surface surveys for six seasons and test diggings at four sites. Due to lack of resources, systematic survey techniques (see Ammerman 1981; Dunnell and Dancey 1983; Schiffer et al. 1978) could not be used in this study. Hence, a different strategy known as "purposive technique" (Schiffer et al. 1978:5), in which the areas around critical resources are surveyed, was used. As a part of this strategy the neighborhood of the critical resources such as plant and animal foods and water sources, and also the vicinities of caves and rockshelters, hills and rock outcrops were intensively surveyed for detecting archaeological remains. The critical resources were identified based on map study

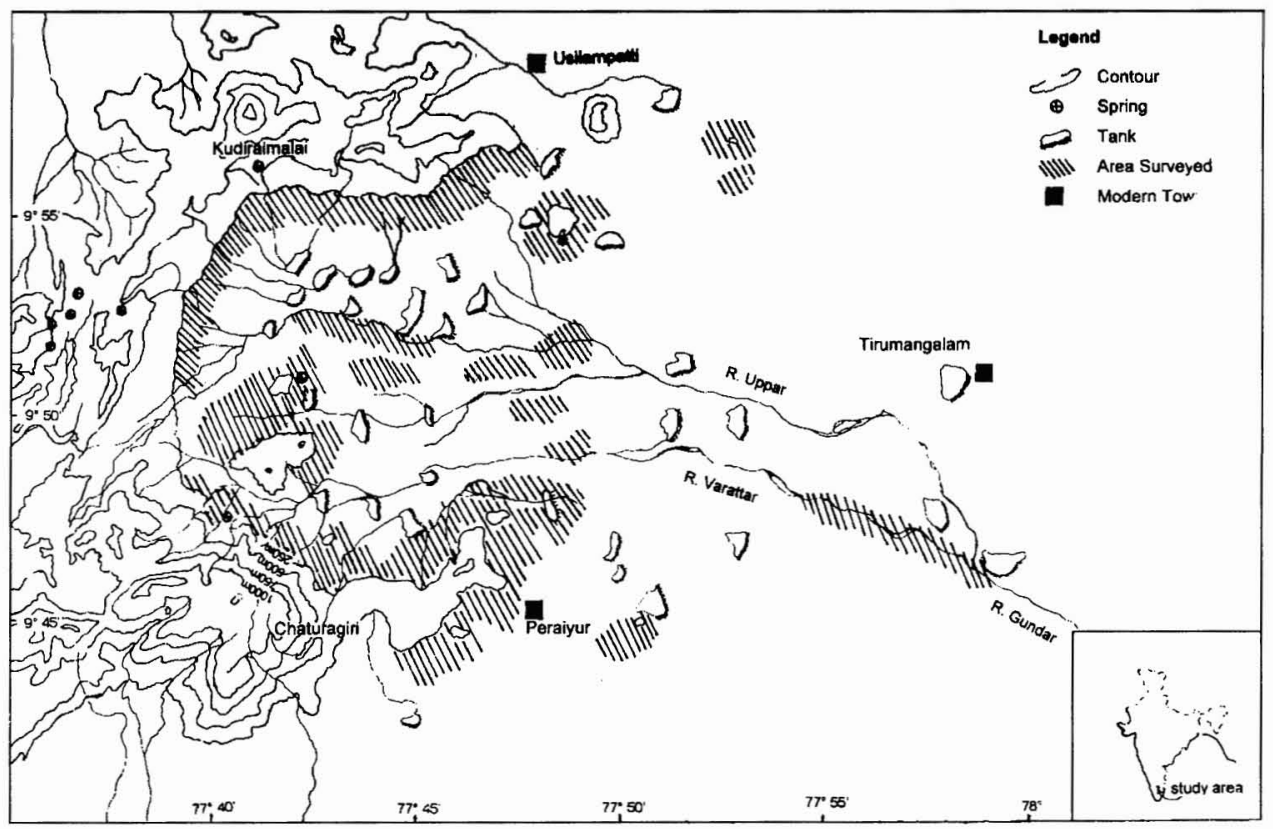

Fig. 1. Areas surveyed in the upper Gundar Basin. 
and enquiries made to the local people. A $2-\mathrm{km}$ radius around the resources was surveyed by individuals walking fields at intervals of about $100 \mathrm{~m}$. The areas around the resources, which have dense scrub forest cover and hilly terrain, could not be surveyed because of poor visibility and accessibility. An area of $1 \mathrm{~km}$ from the edge of hillocks and rock outcrops was surveyed. In order to avoid any bias that normally emerges in this type of survey, the black-soil plain lying in the middle of the basin, which is devoid of any rock outcrops and critical resources, was also surveyed at three locales. Though systematic and intensive survey methods could not be adopted, the significance of recording the distribution of artifacts on the landscape rather than the few points generally known as "sites" was taken into consideration and efforts were made to identify and record the low-density scatters and the isolated cultural materials, which are also known as "off-sites" (Foley 1981; Rossignol and Wandsnider 1992). In addition, the sections exposed in the streams and wells were also inspected to identify buried artifact horizons. Density of artifacts and the size of the area were the criteria used to distinguish "sites" and artifact scatters.

\section{SITE CATEGORIES}

Surface surveys have revealed 109 microlithic sites in this basin. These microlithic sites have been broadly divided into three groups, Category 1, Category 2, and Category 3 , based on their size and artifact density. On the fringes of the basin at several localities, where artifacts are found continuously in varying concentrations, it was difficult to demarcate the site limits. These localities have been demarcated and are shown as dotted areas in Figure 2.

Category 1: Sites with stray finds of a solitary or a few artifacts are grouped into this category. Thirty-four such off-sites have been located. However, there may be many more sites of this category buried and thereby remain undiscovered. The majority of these sites are located away from the critical resources and are found on the fringes of the basin and a few in the black-soil tract, which lies in the middle of the basin (Fig. 2).

Category 2: Surface scatters, with a low artifact density and covering a specific area but without any thick sediments, fall under this group. There are 66 such sites, which vary in size from $6 \mathrm{~m}^{2}$ to $9600 \mathrm{~m}^{2}$. These sites are also found mostly on the fringes of the basin. However some of the sites occur in the vicinity of critical resources, while others are away from such resources.

Category 3: Sites with thick deposits or a dense scatter of artifacts covering a large area, which resulted due to multiple episodes of occupation, come under this group. There are nine sites in this category: three are rockshelters and the rest are open-air sites. Their size varies between about $8 \mathrm{~m}^{2}$ and $7000 \mathrm{~m}^{2}$. Sites of this category are situated near resources such as water and rockshelters or in the vicinity of strategic locations like elevated ground and the hillocks, which provide a commanding view of the surrounding area.

\section{TEST EXCAVATIONS}

Test excavations were undertaken at the microlithic rockshelter sites of Kanavaypatti, E. Gopalapuram, and Virappatti, and at the open-air site near S. Pappi- 


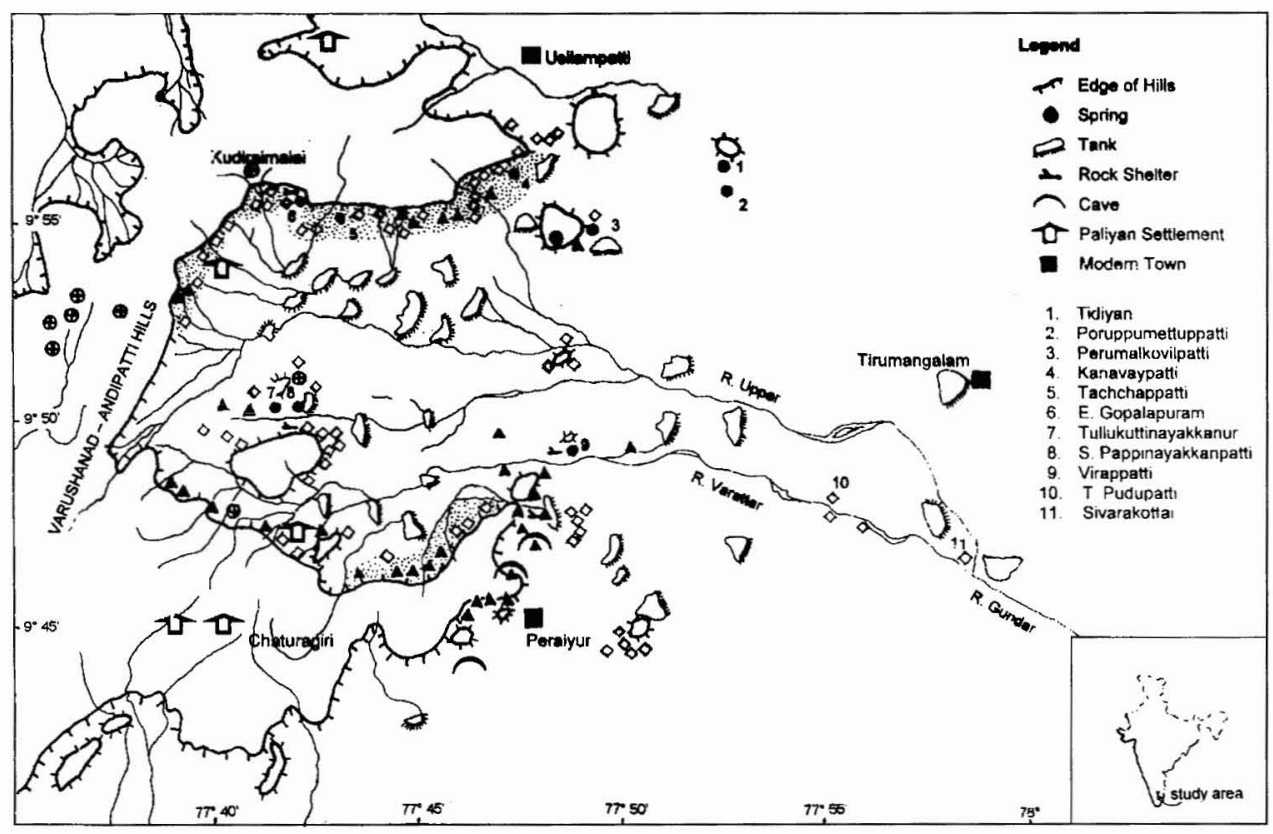

Fig. 2. Microlithic sites in the upper Gundar Basin. Site Categories: Category $1=\boldsymbol{\Lambda}$, Category $2=\diamond$, Category $3=\bullet$.

nayakkanpatti in order to understand their chronological and cultural contexts and also the nature of occupation.

Kanavaypatti (long. $77^{\circ} 52^{\prime} 20^{\prime \prime}$ E; lat. $9^{\circ} 55^{\prime} 72^{\prime \prime} \mathrm{N}$ ). A trench measuring 1.5by $-1.5 \mathrm{~m}$ was excavated in the northern part of the shelter formed by a massive monolithic rock (approximate height, $10.4 \mathrm{~m}$ ) lying $2 \mathrm{~km}$ northwest of the town of Kanavaypatti, which is $6 \mathrm{~km}$ south of Usilampatti. The $0.7-0.8-\mathrm{m}$-thick deposit exposed in this trench was strongly cemented with calcrete and consisted of several occupation floors. Apart from the artifacts, the sediment also contained several rock fragments derived from the exfoliation of the monolith and several gastropod shells of nonhuman origin. ${ }^{1}$ The nature of the evidence found in this trench suggests that this shelter witnessed numerous episodes of occupation spanning several centuries. Despite the absence of any major variation in stratigraphy, on the basis of the artifactual evidence the deposit can be divided into two periods.

Period I, the Mesolithic, has yielded a large number of microlithic artifacts, principally made of quartz, hammerstones, wild animal bones, charcoal fragments, and burned clay pieces. Domestic animal bones were absent, apart from a sheep/ goat bone, which may be considered a later intrusion.

Period II, the Iron Age-Early Historic, brought to light 32 pottery fragments of the Iron Age and Historic periods, several domestic and wild animal bones, and a few dressed stone slabs and grinding stones, besides the artifacts and features identical to those found in Period I.

E. Gopalapuram (long. $77^{\circ} 41^{\prime} 29^{\prime \prime}$ E; lat. $9^{\circ} 54^{\prime} 11^{\prime \prime} N$ ). E. Gopalapuram lies $2 \mathrm{~km}$ northwest of Elumalai, which is $18 \mathrm{~km}$ from Usilampatti by road. Two 


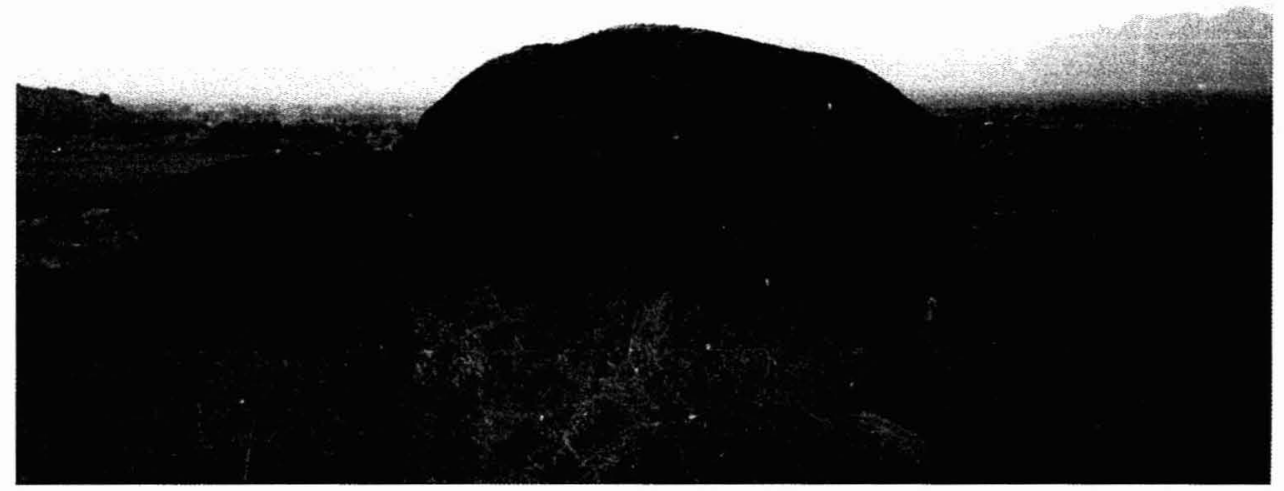

Fig. 3. View of the rockshelter (Trench I) at E. Gopalapuram. Such rockshelters abound in the upper Gundar Basin. The ancient hunter-gatherers used the shelters, which are located close to resources.

kilometers northeast of E. Gopalapuram at the foot of the Kudiraimalai hill, there is a mushroom-shaped monolithic rock, known as Rajankal, with two overhangs on its eastern and western faces (Fig. 3). Two test trenches, each measuring 1 $\mathrm{m}^{2}$-one in the western shelter and the other in the eastern-were excavated. These trenches produced microliths along with a few fragments of Iron Age and Historical period pottery from the lower-most levels. The trench excavated in the western shelter (Fig. 4) had a very limited number of artifacts in the lower levels, whereas its upper levels had a relatively higher quantity of artifacts.

Virappatti (long. $77^{\circ} 53^{\prime} 9^{\prime \prime}$ E; lat. $9^{\circ} 52^{\prime} 56^{\prime \prime} \mathrm{N}$ ). Virappatti is located $2 \mathrm{~km}$ east of Mangalarevu, which is $17 \mathrm{~km}$ south of Usilampatti on the Peraiyur road. A few microlithic scatters are found on the northwestern side of the village near a hillock (197 AMSL). There is also an Iron Age-Early Historic (Megalithic) burial (cairn-circle) near the hillock. One hundred meters further southeast of the hillock is a massive monolithic rock, known as 'Nayakkanparai,' which provides shelter on the northwestern side. Very few microliths and Iron Age-Early Historic period pottery are found on the surface of the shelter. With a view to finding out the relationship between pottery and lithic artifacts, a trench measuring 2-by-1 $\mathrm{m}$ was dug in this shelter. This trench exposed a $0.7-\mathrm{m}$-thick deposit belonging to the Iron Age-Early Historic period. It had a large amount of microlithic artifacts, a small quantity of Iron Age-Early Historic pottery and animal bones, traces of iron smelting activities such as iron slag, and a few fragmentary terracotta pipes and iron objects. Fig. 5 shows the test trench with an iron object in situ.

S. Pappinayakkanpatti (long. $77^{\circ} 42^{\prime} 11^{\prime \prime}$ E; lat. $9^{\circ} 48^{\prime} 52^{\prime \prime}$ N). S. Pappinayakkanpatti lies $3 \mathrm{~km}$ southeast of Elumalai. A trench measuring 2-by-2 $\mathrm{m}$ was excavated in the Early Historic agropastoral settlement situated about $1 \mathrm{~km}$ southwest of the village near a hillock (Fig. 6). It revealed an aceramic microlithic horizon, 1 to $1.80 \mathrm{~m}$ below surface level, underneath an Early Historic deposit. The dis- 


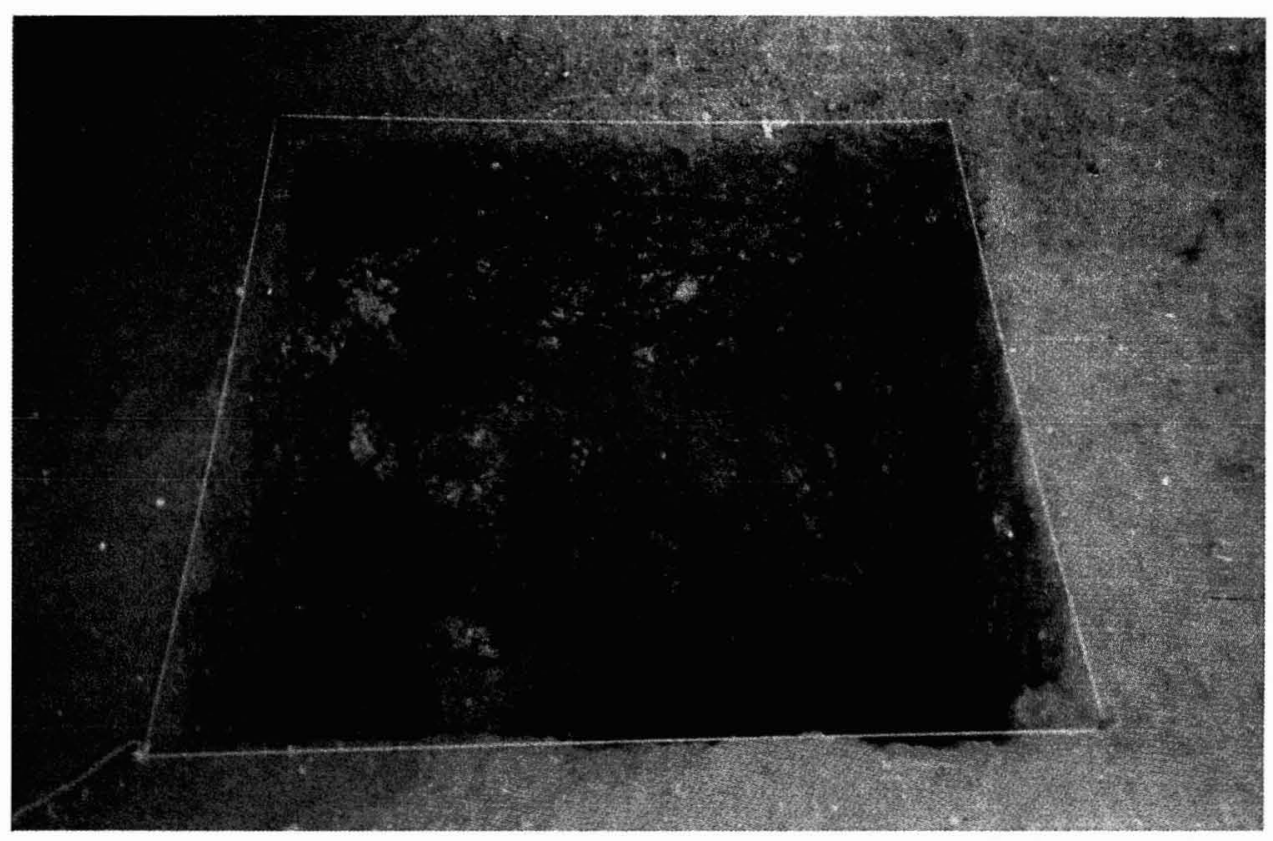

Fig. 4. The test trench excavated on the western side of the rockshelter at E. Gopalapuram. This trench yielded quartz artifacts mixed with historical pottery.

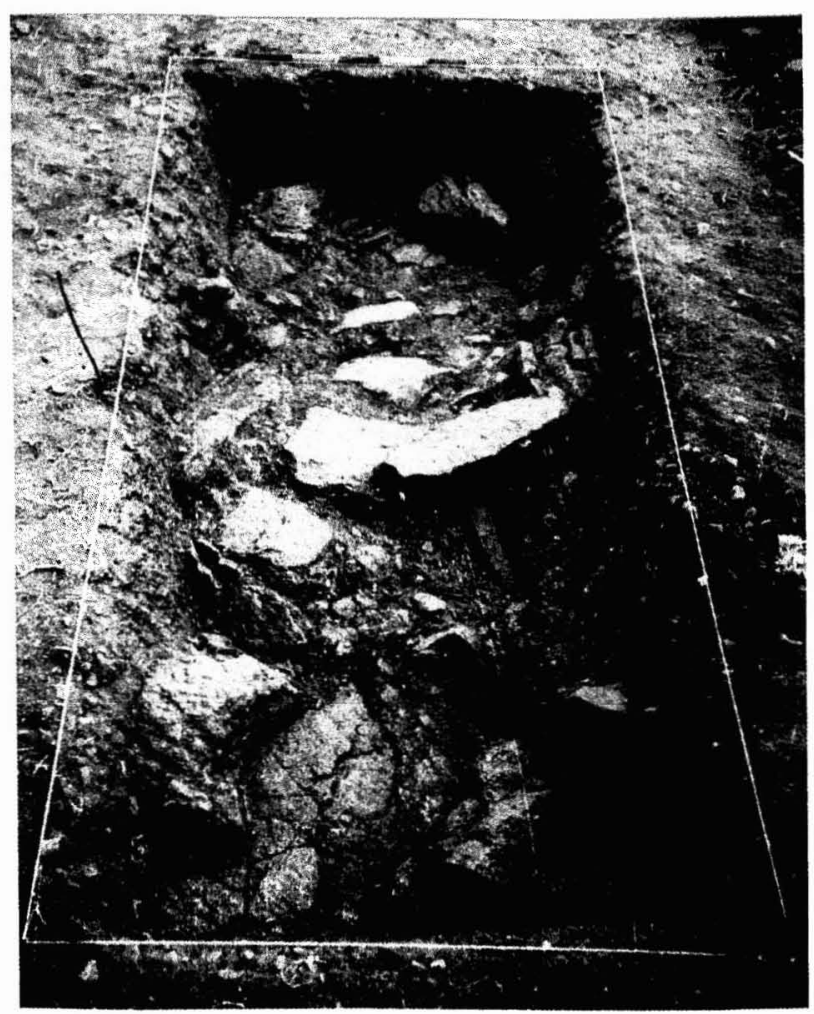

Fig. 5. The trench at Virappatti with an iron object in situ. Several groups at different points in time perhaps used this shelter. 


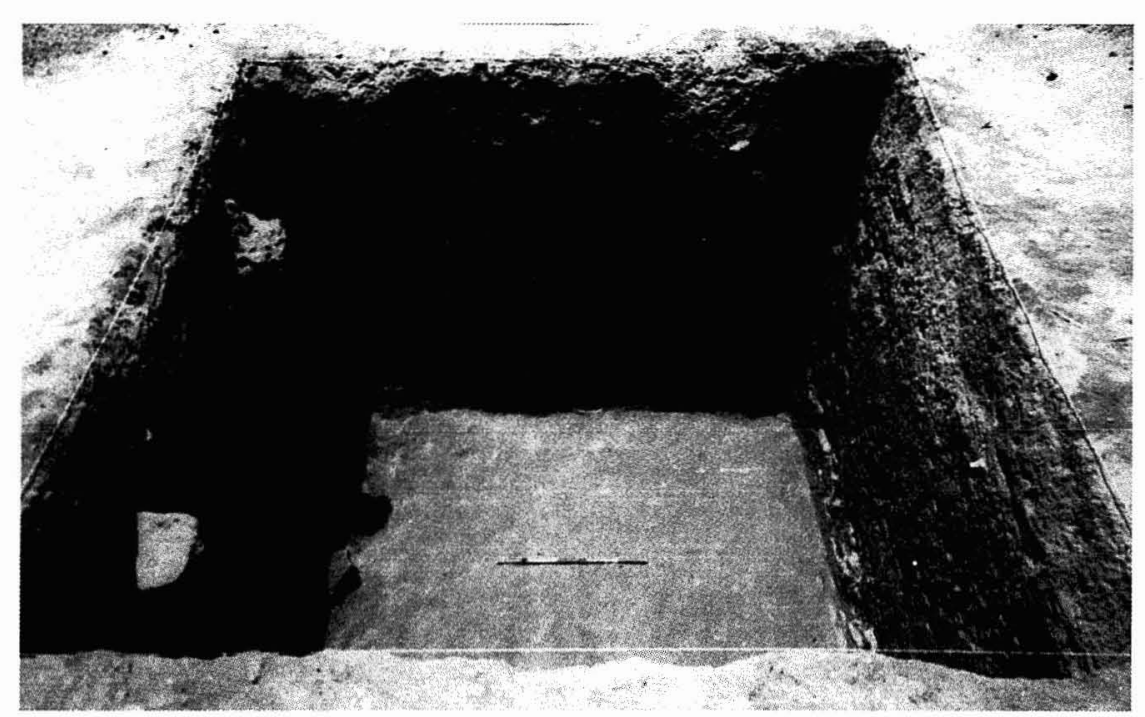

Fig. 6. The trench at S. Pappinayakkanpatti. Here the Mesolithic deposit underlies the Early Historic deposit.

covery of the microlithic horizon was unexpected, as no clues to the buried microliths were on the surface. The microliths occur in a red loam formed due to in situ weathering of granite rocks. The top level of the Mesolithic occupation was heavily disturbed up to a depth of $1.30 \mathrm{~m}$ by the pits dug during the Early Historic period. This Mesolithic level yielded mostly microliths and a few small teeth fragments of some unidentifiable animal species; but no manuports or heavy-duty tools (large tools, more than $5 \mathrm{~cm}$ in size) were found. At a depth of about $1 \mathrm{~m}$ below surface level, fragmentary remains of articulated human femur bones were uncovered in a highly decayed condition. The Early Historic settlers subsequently disturbed this burial, which seems to belong to the Mesolithic period.

\section{NATURE OF THE ARCHAEOLOGICAL RECORD AND SITE CONTEXTS}

The location of the Gundar Basin in the rain shadow of the southwest monsoon pattern and the smaller size of its catchment and drainage, which are some of the characteristics of a low-energy environment, have minimized the impact of natural agencies on the archaeological record. The activities of the natural forces acting upon the basin at present provide valuable clues to understand the natural processes that could have contributed to the present-day configuration of the archaeological record. Observations made in the basin show that erosional activities are intensive near the rills and the streams, and the depositional activities are active in the low-lying areas. Hence, a relatively higher degree of modification, like displacement and burial of artifacts, specifically of the low-density scatters (Category 1), might have taken place mostly in the neighborhood of the rills, streams, and rivers, and more so in the eastern part of the basin, below the $140 \mathrm{~m}$ contour as noticed at T. Pudupatti. At this site both rolled and fresh artifacts, 
perhaps derived from two different contexts, occur together. Other sites which are in the rockshelters and in the uplands, away from the intensive erosional range of the streams and rivers, appear to have remained largely unaffected. Supporting evidence for this observation is the nature of the artifacts including their freshness and also the microartifacts recovered from the excavated sites. Among the animal bones found in the sites, only one bone fragment from Kanavaypatti showed gnaw marks. Despite these minor disturbances, it can be concluded that the majority of the sites discovered so far in this basin, except for T. Pudupatti, were probably affected by natural agencies only to a limited extent.

The impact of cultural activities of succeeding periods is also an important factor contributing to the formation of the archaeological record of a particular period. Some of the determinant factors of settlement patterns such as preference to establish the settlements adjacent to water sources, which are similar for both the prehistoric and modern hunter-gatherer communities, cause the frequent reoccupation and reuse of ancient sites located near critical resources. ${ }^{2}$ Such reuse decreases the visibility of the earlier portions of the archaeological record as observed at S. Pappinayakkanpatti, where no clues for the Mesolithic horizon covered by the Early Historic deposit were found on the surface. Similar buried deposits can also be expected beneath a few of the Iron Age-Early Historic and Medieval habitation sites of this basin. The Iron Age-Early Historic people have also chosen some of the pre-Iron Age microlithic sites for burying the dead, and as a result modified the earlier remains considerably.

Cultivation and related activities, which have been going on in this basin for several centuries, too, have considerably affected the archaeological sites. The larger artifacts (more than $4 \mathrm{~cm}$ across) that hinder agricultural activities are generally collected by the farmers and discarded along the boundary of the fields, while the smaller ones are left untouched. Plowing buries the microliths and affects their visibility, more in the case of the low-density scatters. Some of the uncultivated areas near the hill fringes, which had a few microlithic scatters (site Categories 1 and 2) in 1992-1993, became completely invisible in 1996 after they were brought under cultivation. Although plowing does not seem to cause largescale displacement of the microliths, the removal of vegetation cover, which protects the microliths from erosional activities, indirectly exposes them to displacement in the areas that have a steep gradient.

One of the main issues of the present research concerns the cooccurrence of artifacts such as pottery, domestic animal bones, lithic artifacts, and iron objects at the rockshelter sites. It is necessary to consider the formation processes under circumstances such as physical association, which can arise as a result of diverse factors, does not always warrant an inference of contemporaneity. Here the role of natural agencies in causing this association seems to be very meager, and one or more of the following reasons could have been responsible for generating such an association.

1. The material evidence in the rockshelters resulted only due to activities like occasional camping by the (iron using) agropastoral groups.

2. Intrusion of pottery and domestic animal bones into the pure Mesolithic record during a later period.

3. Occupation of these sites by hunter-gatherers, agropastoral groups, and other groups on different occasions. 
Table i. Chronological Context of the Microlithic Sites from the UpPer Gundar Basin

CONTEXT

Mesolithic or Pre-Iron Age

Iron Age and Historical

Mixed or context uncertain
NAME OF THE SITES

Kanavaypatti Period I and S. Pappinayakkanpatti Period I

E. Gopalapuram, Virappatti, and Kanavaypatti Period II

All the surface scatters (Categories 1 and 2) and the unexcavated high-density sites (Category 3 )

4. Interactions between hunter-gatherers and agropastoralists.

5. Microlith-using agropastoralists (impoverished, without access to iron).

The first two propositions assume that the hunter-gatherers had no role in the formation of these deposits and they were not contemporaneous with agropastoral groups. However, in archaeological context there is clear evidence for the presence of hunter-gatherers during the Iron Age-Early Historic period. The stratigraphic evidence from the excavated sites also shows that these materials were not later intrusions into the Mesolithic record.

It appears that there were at least two distinct groups, the agropastoralists and hunter-gatherers, living in the basin during the Iron Age-Early Historic period. Though identification of ('ethnic') groups in archaeology is generally considered highly risky (Atherton 1983; DeCorse 1989; Hassan 1987:3; Shennan 1989), in this context there are valid reasons for distinguishing the archaeological sites of the agropastoralists and hunter-gatherers. First, the agropastoral groups, who had iron technology, need not have engaged in such large-scale quartz knapping as seen in the rockshelter sites, though they used a limited range of lithic (mostly made of chert) and bone tools. Second, there is a temporal continuity in the occupation of the rockshelter at Kanavaypatti from the Mesolithic to the Iron AgeEarly Historic period and technological similarity of lithic industries, which point to the continuing existence of hunter-gatherers in the post-Mesolithic period. The characterization of agropastoral communities in the Early Historic Sangam Tamil literature suggests that the possibility of these sites being created by microlithic-using, impoverished pastoralists is low (Singaravelu 1969; Zvelebil 1975). The microlithic sites in the basin can be grouped into three contexts (Table 1).

\section{PERIODIZATION AND CHRONOLOGY}

The Mesolithic phase is the earliest cultural phase that has been clearly represented in this region and no clear-cut evidence for the Palaeolithic has been discovered so far. It has to be mentioned here that Raman (1970) assigned the heavy-duty artifacts he found at T. Pudupatti and Sivarakottai to the Middle Palaeolithic (Series II). During the recent investigations, a limited number of similar heavy-duty artifacts were noticed at Perumalkoilpatti and Vittilpatti in surface contexts together with microliths. It appears that these artifacts could have formed a part of the tool kit of the Mesolithic groups rather than representing a different techno-tradition, as evidence for the association of microliths and heavy-duty tools are available from the eastern parts of India (Mohanty 1993; Ota 1986). 
However, more investigation is necessary in this regard. Some of the workers have dated all the microlithic sites found in this area to the Mesolithic period (Raman 1970; Vedachalam 1985). Earlier, Zeuner and Allchin (1956:20) had postulated a sequence of three microlithic industries for the Tamil Nadu coast. Raman (1970) disagreed with them regarding the presence of the third microlithic industry, associated with the Neolithic culture in southern Tamil Nadu. Citing the absence of evidence for the Neolithic sites there, he contended that all the microlithic sites that were brought to light during his surveys in this region belonged to the Mesolithic period. From the stratigraphic and artifactual evidence recovered during the recent investigations, it is clear that the microlithic sites of this basin can be ascribed to two chronological contexts, the Mesolithic and the Iron Age-Early Historic periods (Selvakumar 2001).

Evidence for the Mesolithic period was found in the test excavations at S. Pappinayakkanpatti and Kanavaypatti. While at S. Pappinayakkanpatti the Mesolithic deposit lies below the Early Historic remains of agropastoral groups, at Kanavaypatti it is overlain by a deposit comprising microliths, animal bones, and pottery, which was mostly a result of the occupation of the Iron Age-Early Historic hunter-gatherers.

In the Iron Age-Early Historic period, microliths occur in two distinct cultural contexts. A limited quantity of microliths found along with a large amount of pottery, and other artifacts in the village-type habitation sites are identified as the settlements of agropastoral groups (not included on the map here, see Selvakumar 2000: Fig. 2). The rockshelter sites, which have a large quantity of microliths and a few pottery fragments and located mainly in the marginal areas of the basin, were mostly occupied by hunter-gatherers, and agropastoral groups could have periodically used these sites as well. Evidence for the latter context is found at Virappatti, E. Gopalapuram, and Kanavaypatti Period II.

There are no radiocarbon dates available for the Mesolithic and postMesolithic hunter-gatherer sites of the upper Gundar Basin. The two charcoal samples from the test trench at Virappatti, assayed by the Physical Research Laboratory, Ahmedabad, turned out to be modern (PRL 1800 and 1801). ${ }^{3}$ In the absence of radiocarbon dates, the Mesolithic remains can only be tentatively dated on the basis of the dates given to other Indian Mesolithic sites. In India, with the support of several radiocarbon dates, the Mesolithic period is generally placed between c. 10,000 B.P. and c. 4000 B.P. (for a detailed discussion, see Deraniyagala 1992:110-112; Kennedy et al. 1992; Possehl 1994). The fluorine-phosphate analyses of bones from Mesolithic sites of the upper Gundar Basin also show values similar to those from other Indian Mesolithic sites (Kshirsagar 1993; Selvakumar 1997: Table 60). Therefore, taking these facts into consideration, the beginning of the Mesolithic in the Gundar Basin can be tentatively dated to the early Holocene period. However, it has to be noted that the neighboring Sri Lankan microlithic sites have much older dates, i.e., 28,500 B.P. (Deraniyagala 1992:118, 472-479). Unlike the Teri sites of southeast India, where microliths occur on the surface of the red sand dunes, the Sri Lankan sites yield microliths below the sand dunes. In India, very few Mesolithic sites have given early Holocene dates. Most of the radiocarbon dates are in the post-mid-Holocene time bracket. Hence, there is no substantial evidence at present to date the Indian microlithic sites beyond the Holocene. 
The presence of the Iron Age and Early Historic pottery at a few microlithic sites is a clear pointer to the continuing survival of hunter-gatherers up to the Early Historic period. In spite of the absence of radiocarbon dates from the Gundar Basin, the stratigraphic and ceramic evidence suggests that the Iron Age must have begun before the mid-first millennium B.C. For dating the Early Historic period, there is ample data, including a radiocarbon date from the Early Historic agropastoral settlement at S. Pappinayakkanpatti (PRL NO. 1965: $2040 \pm 150$ B.P.). ${ }^{4}$ Based on this evidence, the Iron Age-Early Historic period can be dated to c. 500 B.C. to A.D. 500. It is uncertain whether the microliths were used by hunter-gatherers as late as the Medieval period. It is interesting to note that the Paliyans, who live in the Varushanad-Andipatti hill range, were using quartz and steel for making fire until a few decades ago (P. M. Gardner 1972:417). More investigation on the sites occupied by the Paliyans during the Medieval and recent periods would reveal whether they used the lithic artifacts during the postEarly Historic period.

\section{ETHNOGRAPHIC DATA}

Ethnographic data on the Paliyans and other groups living in the Gundar Basin have been used in this study to understand hunter-gatherer adaptations during the Mesolithic and Iron Age-Early Historic periods. The Paliyans are a huntergatherer group living in the Varushanad-Andipatti hills and on its fringes and in other hill areas of southern Tamil Nadu (Census of India 1969; Gardner 1972; Thurston and Rangachari 1909). P. M. Gardner's work on the Paliyans focused on their socio-economic aspects (Gardner 1965, 1966, 1969, 1972, 1982, 1984). The Paliyans used to disperse into small groups in the summer months because of a reduction in their food supply. The contemporary Paliyans do not strictly follow a hunting-gathering way of life and very few of them live in the hills, which is their original habitat. Most of the group lives on the hill fringes in concrete houses built by the state government of Tamil Nadu and collect forest products and sell them in the local market. They exploit their original habitat in groups of two to five individuals and then move back to the settlements at the end of the day. The ethnographic study undertaken by the author focused on the subsistence and settlement patterns of the Paliyans and their interactions with the agropastoral groups. Information regarding the ancient mobility pattern of the Paliyans was collected on the basis of the enquiries made to elderly Paliyans.

\section{THE LITHIC INDUSTRY}

The lithic industry of hunter-gatherers of the upper Gundar Basin is dominated by the microlithic elements consisting of both geometric and nongeometric tools, mostly fashioned on flakes (Figs. 7, 8). This industry also has a limited amount of heavy-duty tools, largely made on cherty quartzite. A total of 13,260 artifacts consisting microliths and heavy-duty tools were collected from the basin by three different means (Table 2). ${ }^{5}$ Since the uncontrolled (random) collection undertaken in the first season (in 1992) could not be considered a representative sample of the lithic industry of hunter-gatherers, a systematic collection of artifacts was made at four sites from a total of 38 grids (the grid size was $1 \mathrm{~m}^{2}$ ) from three 


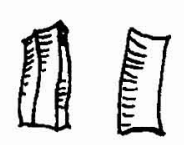

A

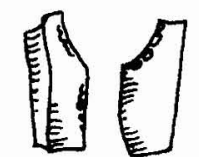

B

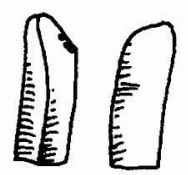

C
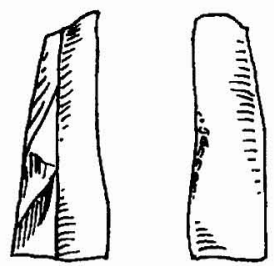

D

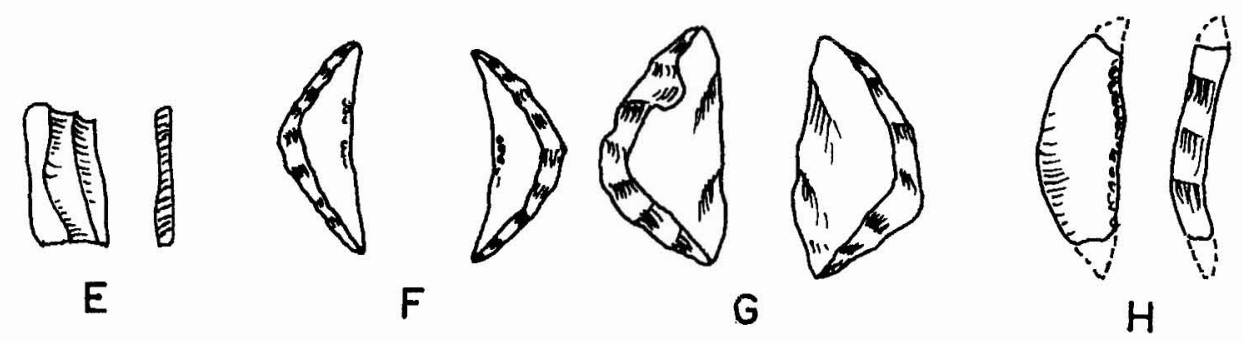

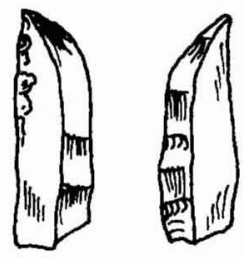

I
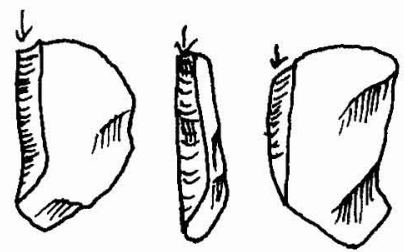

J
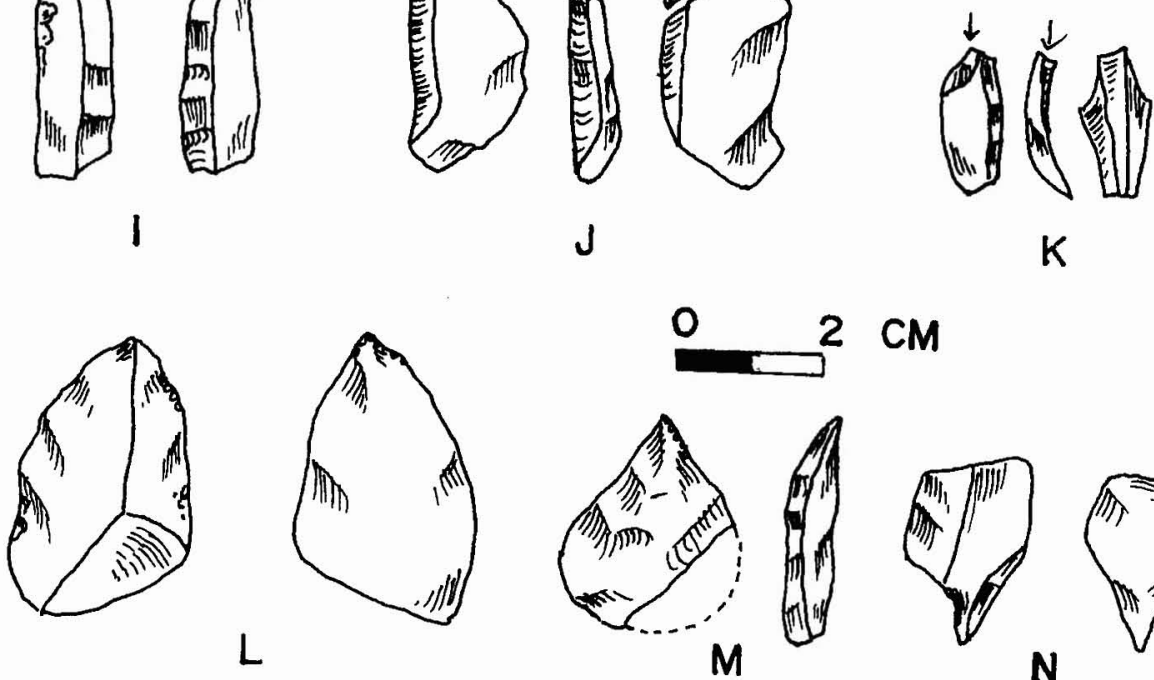

$2 \mathrm{CM}$
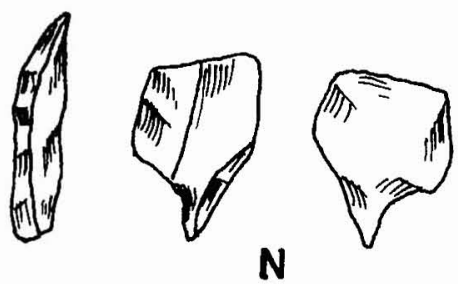

$\mathbf{N}$

Fig. 7. a-d: retouched blade; e: backed blade; $f-g$ : triangles; $h$ : lunate; i: penknife; $j-k$ : burin; $1-m$ : point; n: borer.

Category 3 sites, and four grids from a Category 2 site. However, in the case of low-density scatters, the random surface collection can be treated as representative in view of the fact that at several of the low-density scatters a majority of the artifacts were collected.

Because of the mixed character of assemblages it was difficult to decide on any specific reasonable unit for analyzing the lithic artifacts. At one level, the entire 


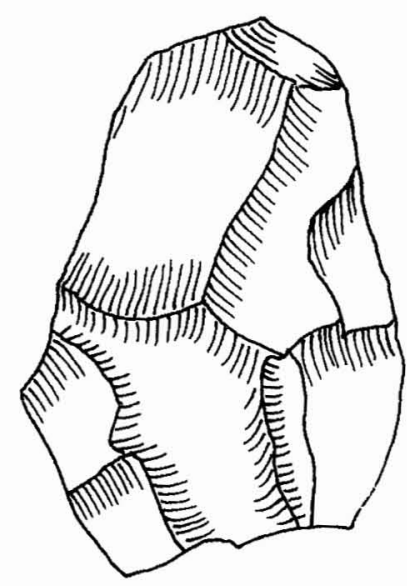

A
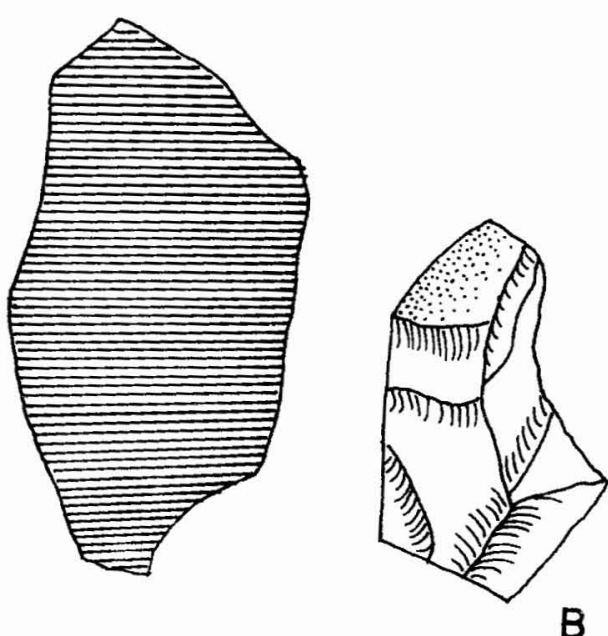

B

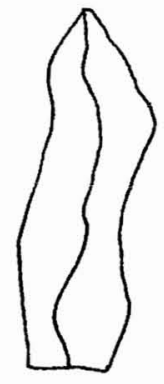

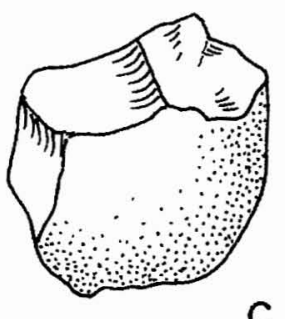

C

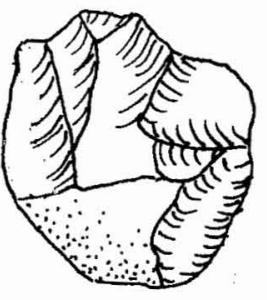

$E$

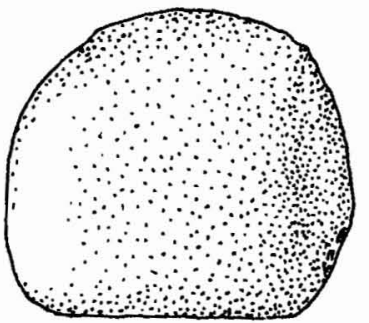

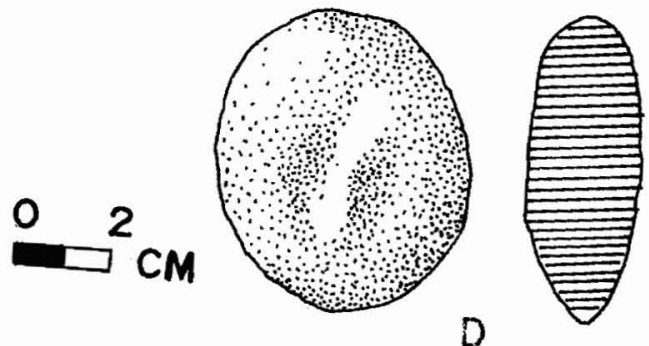
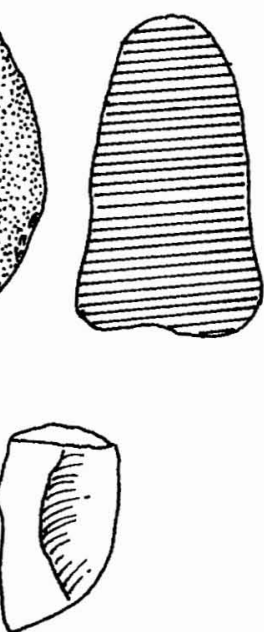

G
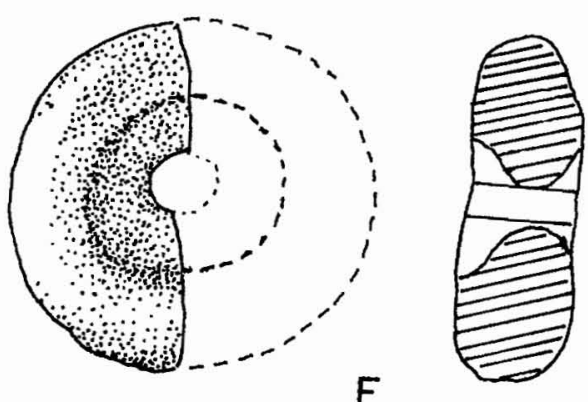

$F$

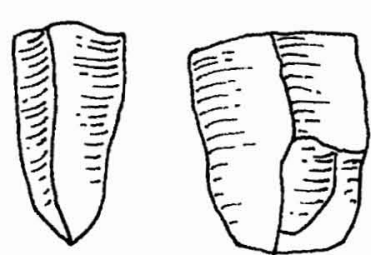

H

Fig. 8. a, c: chopper; b: knife; d: hammerstone; e: grinding stone; f: ringstone; g-h: blade core. 
Table 2. Sources of the Lithic Collection

\begin{tabular}{lr}
\hline SOURCES OF THE ARTIFACTS & NUMBER OF ARTIFACTS COLLECTED \\
\hline Uncontrolled surface collection & 1271 \\
Systematic surface collection & 923 \\
From the test trenches at Kanavaypatti, Virappatti, & 11,066 \\
$\quad$ E. Gopalapuram, and S. Pappinayakkanpatti & 13,260 \\
$\quad$ Total & \\
\hline
\end{tabular}

collection, which can be taken to represent the lithic industry of hunter-gatherer groups of the Mesolithic and the Iron Age-Early Historic periods, was treated as one unit and analyzed. At another level, the assemblages from the excavated sites, which can be chronologically segregated into the Mesolithic and Iron Age-Early Historic periods are analyzed separately and the results are presented at the end of this section (Table 3 and Table 4). Only a preliminary analysis of the artifacts is presented here. A modified version of the classification schemes of Clark and Kleindienst (1974:71-105) and Sankalia (1964) is employed for the analysis of the artifacts. The term 'heavy-duty' is used to refer to artifacts that are larger than $5 \mathrm{~cm}$ across. The term 'chip' means tiny flakes, which are by-products of secondary working and generally smaller than $3 \mathrm{~cm}$. The term 'chunk' refers to amorphous quartz blocks with flake scars. Because microwear (use-wear) analysis was not carried out, function is assigned to the artifacts on stylistic and morphological grounds.

The artifacts have been broadly classified into finished implements, modified pieces, and debitage.

Finished implements include artifacts that have specific design or shape and bear some amount of secondary working. Under this class fall blades, crescents, triangles, penknives, burins, points, borers, scrapers, choppers, and ringstones, which form 2.66 percent (354) of the 13,260 artifacts collected. Out of the total 199 microlithic implements other than the blades, only 17 are made on blades and the rest are on flakes.

Modified pieces encompasses blades and flakes possessing traces of modification and use, and hammerstones, grinding stones, and querns, representing 4.01 percent (532) of the collection.

Simple flakes/blanks, chips, chunks, nodules, crystals, core rejuvenation flakes, and blade-core preparation flakes are grouped in the debitage category. They constitute a major proportion of the lithic material, constituting 93.31 percent $(12,373)$ of the collection.

\section{Choice of Raw Material}

Quartz is the principal raw material used by the hunter-gatherers in the Gundar Basin (Fig. 9). It appears that the paucity of easily workable raw materials, such as chalcedony and chert, compelled hunter-gatherers to opt for quartz, which occurs profusely in this area. Irrespective of its numerical dominance, quartz is comparatively less represented among the finished implements than any other material. Due to its intractable nature, it yields a large quantity of debitage. A similar 
Table 3. Frequency Distribution of Lithic Artifacts from Mesolithic Hunter-Gatherer Sites of the Upper Gundar Basin

\begin{tabular}{|c|c|c|c|c|c|c|c|}
\hline & QUARTZ & $\begin{array}{c}\text { CHERTY } \\
\text { QUARTZITE }\end{array}$ & CHERT & JASPER & CHALCEDONY & GNEISS & TOTAL \\
\hline \multicolumn{8}{|l|}{ Finished Implements } \\
\hline Blade & 11 & 2 & - & - & - & - & 13 \\
\hline Burin & 4 & 1 & - & - & - & - & 5 \\
\hline Lunate & 2 & - & - & - & - & - & 2 \\
\hline Triangle & 10 & 1 & - & 1 & - & - & 12 \\
\hline Borer & 5 & - & - & - & 1 & - & 6 \\
\hline Point & 32 & - & 1 & - & 1 & - & 34 \\
\hline Scraper & 6 & 1 & - & - & - & - & 7 \\
\hline Chopper & 3 & 1 & - & - & - & - & 4 \\
\hline Total & 75 & 6 & 1 & 1 & 2 & - & 85 \\
\hline \multicolumn{8}{|l|}{ Modified pieces } \\
\hline Modified flake & 56 & 1 & - & 2 & - & - & 59 \\
\hline Modified blade & 6 & 3 & - & - & - & - & 9 \\
\hline Hammerstone & 4 & - & - & - & - & 1 & 5 \\
\hline Total & 66 & 4 & - & 2 & - & 1 & 73 \\
\hline \multicolumn{8}{|l|}{ Debitage } \\
\hline Blade core & 5 & - & - & - & - & - & 5 \\
\hline Flake core & 30 & 2 & - & - & - & - & 32 \\
\hline Simple blade & 22 & 3 & 5 & 1 & 1 & - & 32 \\
\hline Simple flake & 32 & 1 & 1 & - & - & - & 34 \\
\hline Core rejuvenation flake & 4 & - & - & - & - & - & 4 \\
\hline Blade core & 20 & 4 & - & - & 1 & - & 25 \\
\hline Chip & 2740 & 104 & 18 & 21 & 4 & - & 2887 \\
\hline Raw material & 60 & 3 & - & - & - & - & 63 \\
\hline Chunk & 90 & 1 & - & 1 & - & - & 92 \\
\hline Shatter & 113 & - & - & - & - & - & 113 \\
\hline Total & 3116 & 118 & 24 & 23 & 6 & - & 3287 \\
\hline Grand Total & 3257 & 128 & 25 & 26 & 8 & 1 & 3445 \\
\hline
\end{tabular}


Table 4. Frequency Distribution of Lithic Artifacts from the Iron Age-Early Historic Hunter-Gatherer Sites of THE UPPER GUNDAR BASIN

\begin{tabular}{|c|c|c|c|c|c|c|c|c|}
\hline & QUARTZ & $\begin{array}{c}\text { CHERTY } \\
\text { QUARTZITE }\end{array}$ & CHERT & JASPER & CHALCEDONY & GNEISS & QUARTZITE & TOTAL \\
\hline \multicolumn{9}{|l|}{ Finished Implements } \\
\hline Blade & 14 & - & - & - & - & - & - & 14 \\
\hline Burin & 11 & - & - & - & - & - & - & 11 \\
\hline Lunate & 13 & - & - & - & - & - & - & 13 \\
\hline Triangle & 4 & 2 & - & - & - & - & - & 6 \\
\hline Borer & 3 & 1 & - & - & - & - & - & 4 \\
\hline Point & 27 & 1 & 1 & - & - & - & - & 29 \\
\hline Scraper & 16 & - & - & - & - & - & - & 16 \\
\hline Chopper & 4 & - & - & - & - & - & - & 4 \\
\hline Total & 92 & 4 & 1 & - & - & - & - & 97 \\
\hline \multicolumn{9}{|l|}{ Modified Pieces } \\
\hline Modified flake & 72 & 1 & 一. & - & - & - & - & 73 \\
\hline Modified blade & 8 & - & - & - & - & - & - & 8 \\
\hline Hammerstone & 17 & - & - & - & - & 8 & 1 & 26 \\
\hline Quern & - & - & - & - & - & 2 & - & 2 \\
\hline Total & 97 & 1 & - & - & - & 10 & 1 & 109 \\
\hline \multicolumn{9}{|l|}{ Debitage } \\
\hline Blade core & 17 & - & 4 & - & - & - & - & 21 \\
\hline Flake core & 52 & 1 & - & 1 & - & - & - & 54 \\
\hline Simple blade & 47 & - & 4 & 2 & - & - & - & 53 \\
\hline Simple flake & 52 & 1 & 1 & 1 & - & - & - & 55 \\
\hline Core rejuvenation flake & - & 10 & - & 1 & - & - & - & 11 \\
\hline Blade core & - & 38 & - & - & - & - & - & 38 \\
\hline Chip & 5754 & 154 & 14 & 16 & 9 & - & - & 5947 \\
\hline Raw material & 518 & 2 & - & - & - & - & - & 520 \\
\hline Chunk & 221 & 3 & 1 & - & - & - & - & 225 \\
\hline Shatter & 409 & - & - & - & - & - & - & 409 \\
\hline Total & 7118 & 161 & 25 & 20 & 9 & - & - & 7333 \\
\hline Grand Total & 7307 & 166 & 26 & 20 & 9 & 10 & 1 & 7539 \\
\hline
\end{tabular}




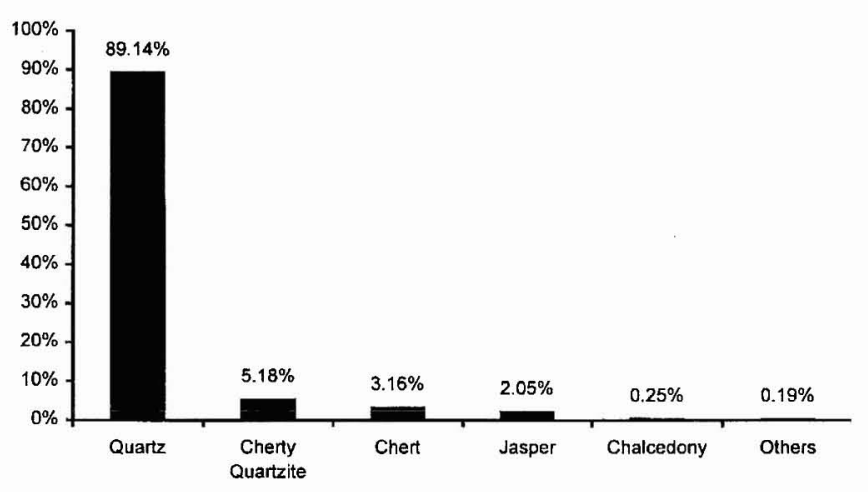

Fig. 9. Frequency distribution of raw materials used in the microlithic industries.

situation is common in the quartz-dominated assemblages from sub-Saharan Africa, Sri Lanka, and the region south of Mysore in India, where other suitable raw materials are not freely available (Bisson 1990:104; Deraniyagala 1992; Hivernel 1986).

Quartz has many variants, such as milky quartz, smoky quartz, and clear quartz. It is available in the basin in the form of veins in granite formations and also as angular chunks at the base of the hills. Quartz crystals and pebbles also occur in the basin, but in very small quantities. Milky quartz was used for manufacturing heavy-duty artifacts, while clear quartz and smoky quartz were preferred for the manufacture of microliths. Evidence from stratified contexts suggests that due to the sharpness of the edges, some of the naturally occurring angular quartz blocks were also probably used without flaking. This can, however, only be ascertained through microwear (use-wear) analysis.

Chert, cherty quartzite, and jasper have been used in small quantities and they form only 10.31 percent of the total collection. Among these materials, chert has a higher percentage of finished implements because of its easily flakeable nature. The source of chert is not known; it probably occurs in association with the Dharwar rock group or it could be of nonlocal origin. The Vaippar Basin (Virudunagar district), lying immediately south of the Gundar Basin, is reported to have chert-bearing limestone deposits (Balachandran, pers. comm. 1992), which could have been exploited. Cherty quartzite, which is available in the basin itself, was also utilized for making heavy-duty tools. One of the main sources of this raw material is T. Krishnapuram, where it was noticed in the exposed section of a well.

\section{Pattern of Artifact Distribution}

The analysis of the lithic artifacts recovered from the different categories of sites revealed the following results.

1. In the sites belonging to Category 3 , the amount of debitage is very high, whereas that of the finished implements is low. The sites of other categories have a very small amount of debitage and a relatively higher percentage of finished implements (Fig. 10).

2. Category 3 sites are dominated by quartz artifacts, whereas Category 1 and 2 sites have a high percentage of chert artifacts (Fig. 11). 


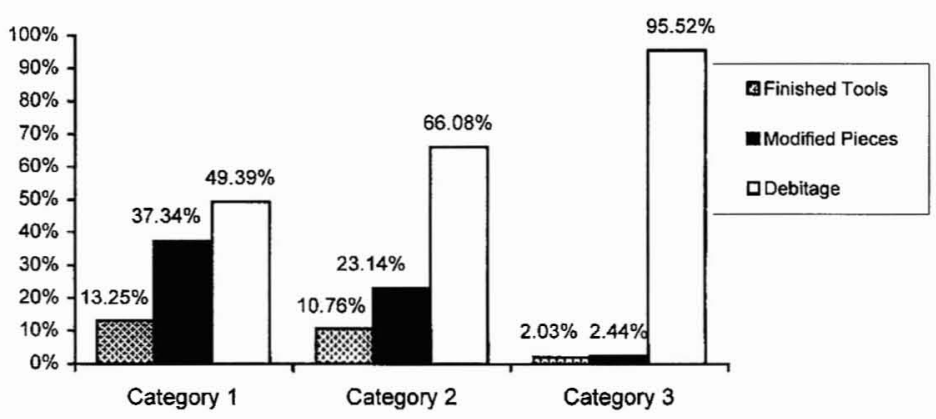

Fig. 10. Frequency distribution of artifact categories in different site categories.

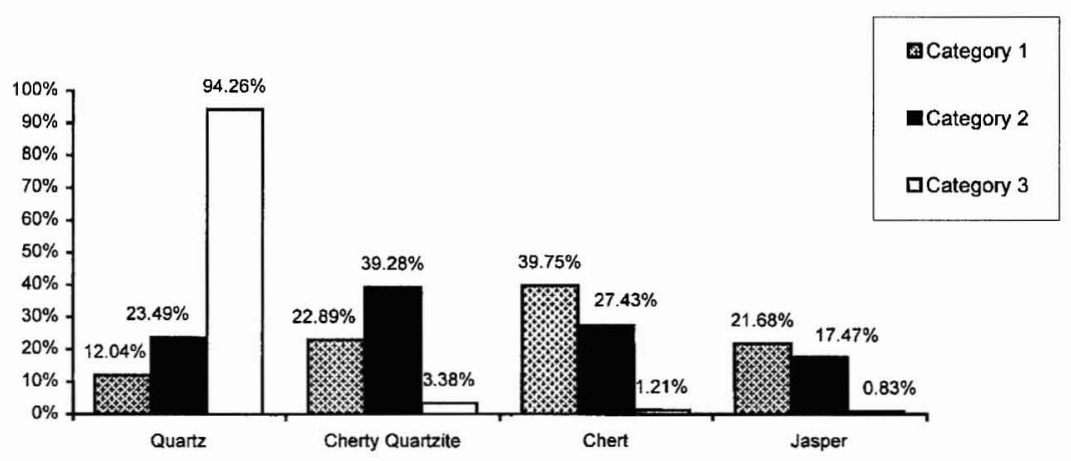

Fig. 11. Distribution of raw materials by site categories.

3. The artifact types from Category 3 sites are varied; in contrast, Category 1 and 2 sites have only a few varieties of artifacts. Permanent features like querns and grinding stones, which are not easily transportable, are confined to the sites of Category 3.

4. Among the finished implements, choppers are more frequent (69.69 percent) in the sites of Categories 1 and 2.

5. Out of a total of 72 blade-core preparation flakes, 70 are from Category 3 sites.

6. No major pattern is seen in the distribution of blade cores. They are almost equally distributed; 54.83 percent of blade cores are from Category 3 sites and the rest are from sites of other categories.

7. In the distribution of simple blades, there is a clear pattern. Of the 111 simple blades, 103 are from Category 3 sites.

\section{Lithic Industries of the Mesolithic and the Iron Age-Early Historic Hunter-Gatherers}

Determination of chronological context was possible only in the case of the lithic assemblages recovered from the test trenches. Out of 11,066 artifacts from the test trenches, 3445 artifacts are from the Mesolithic context, 7539 are from the Iron Age-Early Historic context, and the rest (82) are unstratified. Furthermore, in the frequency of different artifact types, no significant pattern was noticed between 
the lithic industries of the Mesolithic and the Iron Age-Early Historic periods, except in the case of querns and grinding stones. At Kanavaypatti querns and grinding stones are more common in the Iron Age-Early Historic period (two quern fragments and eight grinding stones) than the Mesolithic, which had only one grinding stone. In the distribution of various artifact categories, no remarkable difference was observed: the proportions of the finished implements, modified pieces, and debitage in the Mesolithic assemblage are 2.46 percent, 2.11 percent, and 95.42 percent, respectively, and in the Iron Age-Early Historic contexts, 1.28 percent, 1.44 percent, and 97.26 percent.

A few other patterns were also noticed in the distribution of lithic artifacts: (a) the Mesolithic assemblage from the trench at S. Pappinayakkanpatti had an exceptionally high percentage of points, and (b) overall, the Mesolithic assemblages had a lower proportion of burins, lunates, and scrapers, and a higher proportion of points and triangles than the Iron Age-Early Historic assemblages. These patterns, which are conditioned by several factors, such as the nature of the manufacturing and extractive activities undertaken at the sites on different occasions, and the mode of use, reuse, and disposal of the implements, emerging from the analysis of such a small collection from limited excavations, cannot be taken to represent the general characteristics of the Mesolithic and Iron Age-Early Historic industries. A much closer examination of the lithic assemblages might shed more light on the similarities and differences in the technological and morphological aspects of these industries.

\section{FAUNAL REMAINS}

Several wild and domestic animal bones were recovered from the test trenches excavated at Kanavaypatti and Virappatti and also in surface contexts at Tachchappatti, Andipatti, and Tullukuttinayakkanur (Table 5).

Kanavaypatti: The test trench at Kanavaypatti revealed 163 identifiable bones forming 14.3 percent of the collection, out of which only 79 specimens could be identified specific to species. This collection had both wild and domestic animal species; Period I, the Mesolithic, had only wild animal bones, except for one sheep/goat bone, whereas Period II, the Iron Age-Early Historic, had both. Traces of butchering and charring were noticed on a few bones, while two of them possessed evidence for the use of sharp metal tools for butchering. No bone tools were found, except one, which is ground.

Virappatti: Among the animal bones recovered from the test trench dug at this site, only 11 were identifiable, and the rest of the bones were highly fragmentary splinters. A total of eight bones including one bone each of Bos indicus and Hermitragus hylocrius from Tachchapatti, and 25 bones of Bos/Bubalus, small ruminants, large mammals, and other animals from Tullukuttinayakkanur were collected in surface contexts.

\section{POTTERY}

The test trenches at Kanavaypatti, E. Gopalapuram, and Virappatti produced 32, 214, and 911 pottery fragments, respectively, while at Andipatti 374 fragments were collected from the surface. At Virappatti a few fragments of terracotta pipes 
Table 5. Animal Species Represented in the Faunal Collection from the Hunter-Gatherer Sites of the Upper Gundar Basin

\begin{tabular}{|c|c|c|c|c|c|}
\hline SL. NO. & SPECIES & COMMON NAME & KANAVAYPATTI & VIRAPPATTI & TACHCHAPPATTI* \\
\hline \multicolumn{6}{|l|}{ Wild } \\
\hline 1. & Antilope cervicapra & Black buck & 29 & 3 & 1 ? \\
\hline 2. & Axis axis & Spotted deer/Chital & 1 & - & - \\
\hline 3. & Boselaphas tragocamelus & Blue Bull/Nilgai & 6 & - & - \\
\hline 4. & Cervus unicolor & Deer/Sambar & 4 & - & $1 ?$ \\
\hline 5. & Tetracerus quadricornis & Four-horned antelope/Chowsinga & 1 & - & - \\
\hline 6. & Gazella bennetti & Barasinga & 3 & - & - \\
\hline 8. & Hystrix indica & Porcupine & 1 & - & - \\
\hline 9. & Lepus nigricollis & Hare & - & 1 & - \\
\hline 10. & Vulpes sp. & Jackal/fox & 1 ? & - & - \\
\hline \multicolumn{6}{|c|}{ Domestic } \\
\hline 11. & Bos indicus & Cattle & 14 & 1 & 1 \\
\hline 12. & Bubalus bubalis & Buffalo & 10 & 1 & - \\
\hline 13. & Ovis/Capra & Sheep/Goat & 3 & 2 & 1 \\
\hline \multicolumn{6}{|l|}{ Others } \\
\hline 16. & Equids (smaller) & Horse/Ass & 1 & - & - \\
\hline 17. & Varanus sp. & Monitor lizard & 3 & - & - \\
\hline 18. & Bandicota indica & Mongoose & 1 & - & - \\
\hline 19. & Lissemys punctata & Turtle & 1 & - & - \\
\hline 20. & Lammellidens & Freshwater mussel & 3 & - & - \\
\hline
\end{tabular}

* The animal bones from Tachchappatti are surface collection; the rest are from test trenches. The figure indicates number of identifiable specimens (NISP). 
and crucibles used in iron-smelting activities were also recovered. Though a few of the sherds found on the surface and in the upper levels of the test trenches might belong to the Medieval or modern periods, the fabric and diagnostic forms, such as bowls, lids, and jars, clearly reveal that most of the pottery belongs to the Iron Age-Early Historic period.

\section{OTHER ARTIFACTS}

Artifacts such as a fragmentary bead of amethyst and a double-segmented bead (modern?) at Kanavaypatti; a tubular glass bead waster (cf. Wheeler et al. 1946: 99, Fig. 40), a terracotta spindle whorl with the remains of a 2-mm-thick iron rod inserted through the perforation (cf. Rajan 1994:105, pl. 22) from the surface, and an iron object weighing $1.2 \mathrm{~kg}$ from the test trench at Virappatti; and a disc made out of a pottery fragment by chipping its edges from the test trench at E. Gopalapuram can be assigned to the Iron Age-Early Historic period. The Mesolithic level had only a few mica flakes and hematite pieces retrieved from the test trench at Kanavaypatti. No evidence for hunter-gatherer territoriality such as rock art is found in this basin. The rock art reported so far in the basin appears to belong to the historical period.

\section{PALAEOENVIRONMENT}

There is very limited evidence for the reconstruction of the palaeoenvironmental conditions in the Gundar Basin. Hence, data from the neighboring regions, the faunal remains from the Mesolithic, the Iron Age and the historical sites, and the present-day environment are used for this purpose. Evidence from the Teri sites, which lie about $200 \mathrm{~km}$ southeast of the basin, suggests that humid conditions prevailed in that area around the beginning of the Holocene and the present-day semi-arid conditions came into being during the middle Holocene (R.A.M. Gardner 1995). Similar evidence has also been found in the Nilgiri Mountains, which lie approximately $200 \mathrm{~km}$ northwest of the study area (Gupta 1990; Gupta and Prasad 1985). Several studies on the palaeoclimate show the monsoonal climate, which prevails in the Indian subcontinent, was intense during the early Holocene (Roberts and Wright 1993; Singh et al. 1990; Thompson et al. 1993; VanCampo 1986: 386; Wasson 1995; Wasson et al. 1984). Hence it can safely be assumed that the present-day rainfall pattern would have persisted during the early Holocene on an extensive scale. Thus, the pattern of resource distribution observable in spatial and temporal (annual) scales at present can be projected for the Mesolithic phase.

To facilitate the study of the settlement system of Mesolithic hunter-gatherers, a brief account of the resource distribution in space and time observed in the basin at present is given here. The rainy season (between October and December) creates bountiful water sources and supports the growth of vegetation throughout the area. However, during the dry season there is a sharp decline in the available water and vegetation. In the area east of the upper Gundar Basin (east of long. $77^{\circ} 50^{\prime} \mathrm{E}$ ) the water sources completely dry up, but the upper Gundar Basin has a few perennial water sources. The Andipatti hill ranges and its spurs, and also the isolated hillocks in the upper Gundar Basin, which trap the monsoonal rains and 
release the water through several seep springs, provide adequate water supply during the dry summer months. The summer rains, which are almost regular, replenish these seep springs. The animals that are available on the fringes of the basin would have been present in a higher frequency in the eastern parts of the basin.

Based on the present-day animal migration pattern, it can be suggested that during wet seasons the availability of abundant food supply could have attracted the wild animals into the area east of the basin. The wild animals, which do not go beyond the fringes of the basin, perhaps moved deep into the plains during the pre-Iron Age period when there was no dense human occupation. Similar seasonal animal migration patterns are common in several undisturbed wildlife preserves (Eisenberg and Lockhart 1972; Ramachandran et al. 1986).

\section{SETTLEMENT SYSTEM OF THE MESOLITHIC HUNTER-GATHERERS}

The settlement system approach has emerged as an important methodological tool in archaeological research and it is widely employed to investigate the human interrelationship with their environment (Bettinger 1980; Binford 1972, 1980; Chang 1968, 1972; Jochim 1976; Paddayya 1982; Trigger 1978; Wiley 1953). Various constraints, such as the lack of a chronological resolution at most of the sites, absence of data for reconstructing the palaeoenvironment, the limited scope of the present study, and other factors preclude a complete analysis of the settlement system of Mesolithic hunter-gatherers. Hence, a preliminary attempt has been made to understand some aspects of the Mesolithic settlement system.

The ethnoarchaeological study of contemporary hunter-gatherers furnishes valuable data for developing methods to better understand the settlement systems of the ancient hunter-gatherers (Binford 1980; O'Connell 1995; Yellen 1977). The organizing principles of the hunter-gatherer settlement system is determined by a combination of several factors, such as resource availability, technological adaptation, and certain cultural preferences (Binford 1980; Brantingham 1998; Kelly 1983, 1992; Murdock 1967; Yellen 1977). Taking the organizational aspects involved into consideration, Binford has categorized two kinds of mobility: logistic and residential, among contemporary hunter-gatherers and has attempted to correlate these with the archaeological traces they produce. This model can be adopted to understand the mobility of the Mesolithic groups in the Gundar Basin.

The locational context, size, and artifact density of the microlithic sites suggest that Mesolithic hunter-gatherers used at least two broad and distinct functional locales: base camps and temporary camps/specific activity areas. Several Category 3 site characteristics, such as (a) the abundance of artifacts in general and waste materials, especially quartz, which requires extra time and energy for knapping, (b) a higher proportion of debitage in relation to finished implements, (c) a limited number of sites, and (d) the location close to resources, indicate a high level of redundancy in use and a long duration of occupation. The sites of Categories 1 and 2 were relatively less frequently occupied or were occupied for a short duration because of (a) the small amount of artifacts found at these sites, (b) their higher frequency, and (c) a relatively low proportion of debitage when compared to finished and modified artifacts. Their location in the areas far from resources like rockshelters and water facilities and the distribution in most cases around Category 3 sites also support this claim. Therefore it is quite likely that most of 
the Category 3 sites largely functioned as base camps, forming "hubs of subsistence activities," while sites in Categories 1 and 2 served as temporary camps where extractive and other activities would have taken place. Recurrent shortterm occupations can also result in Category 3 sites and hence, some of the Category 3 sites, e.g., E. Gopalapuram, served as temporary camps. An important point to be noted here is that all the sites in Category 3 need not have functioned as base camps throughout their occupational history. In a particular time period, a base camp could have been used as a special purpose-temporary camp as well. These base camps and temporary camps can be equated, respectively, with Binford's "residential base" and "location" associated with the residential mobility pattern (1980:9). ${ }^{6}$

Most sites in Categories 1 and 2 are located on the slope of the basin fringe. The distribution pattern of sites indicates that this area was perhaps mostly exploited through short-duration camping. The present resource distribution also indicates that this area could have had abundant plant resources, which would have been exploited by the Mesolithic people. The sites in Category 3 are located close to areas that have good water sources. The occurrence of a limited number of Category 3 sites near the basin fringes could be due to the presence of dense jungle cover in those areas. Generally, there is not much variation in the nature of artifacts occurring in the sites in various categories. Choppers are common in Category 2 sites and there are more finished implements than those of Category 3.

Ethnographic information gathered from the Paliyans, who live in the study area, reveals that they used to exploit the resources from such base camps and shift their residences whenever the resources were exhausted in a particular area. Hence, considering this evidence and also the pattern of site distribution, a "residential mobility" pattern can be suggested for Mesolithic hunter-gatherers of the upper Gundar Basin. However, this should not be interpreted to mean that Mesolithic groups had a typical "residential mobility" (i.e., as described by Binford 1980), since these two kinds of mobility are not mutually exclusive (Binford 1980).

The next issue that has to be investigated is the organization of mobility in a particular annual cycle. As the scope of this study is limited, certain tentative propositions on the mobility patterns of Mesolithic groups are put forth here, based on the suggested variation in the distribution of resources and also with the supporting evidence from ethnographic contexts. In order to understand the mobility pattern of a particular hunter-gatherer group, first, the fluctuation in the availability of resources, and second, the preferred segments among the available resources have to be established. As elaborated earlier, during the monsoon and post-monsoon seasons, the resources would have been available in the Gundar Basin and its surroundings, while in the dry season the resources would have mainly been confined to the western part of the upper Gundar Basin. The western part of the upper Gundar Basin with its forested hills, which is home to many species of dioscorea yams (Dioscorea sp.) above $500 \mathrm{~m}$ AMSL and several vegetables like Acacia intisia caesia (mimosa), which are exploited even by the people from the plains during famines (P. M. Gardner 1972:413), would have offered bounteous food supply in the dry months. The area east of the basin (east of longitude $77^{\circ} 50^{\prime} \mathrm{E}$ ) would have had various freshwater, animal, and plant resources as well in the wet seasons. 
With regard to the food preference, it is obvious from the faunal evidence that both big and small animals were hunted (Table 5). Even though no plant remains have been recovered so far from any of the Mesolithic sites, the diverse species of edible plants available in the basin (Selvakumar 1997:178-182) indicate that plant food, such as roots, fruits, and leaves, also would have formed a major source of subsistence for Mesolithic groups. However, the extent of preference of vegetable food is not clear owing to the lack of evidence.

Taking the variation in resources suggested above and also the limited information available on food preference into consideration, it can be proposed that during the post-monsoon seasons, Mesolithic groups subsisted on the resources available in the area to the east of the upper Gundar Basin and during the dry seasons depended on the resources available in the western part of the basin. The proposed animal migration and the abundance of plant resources and freshwater fauna during the monsoon and post-monsoon seasons would have enabled their survival in the area to the east of the basin. In summer when there would be a shortage of such resources in this area, the groups were probably forced to move into the upper Gundar Basin.

Although it is quite likely that Mesolithic groups would have had a similar mobility pattern to that proposed above, resolving the issues as to "aggregationdispersal" (fusion-fission), demographic aspects, and home range is problematic due to the limited nature of the present investigations. The living huntergatherers have different levels and extents of mobility varying from a sedentary one exploiting a small territory to a highly mobile one having several hundreds of square kilometers of home range with differing patterns such as dry-season aggregation and wet season dispersal and vice-versa (Paddayya 1982:89-90). Hunter-gatherers living in the same or identical environment have different types of mobility patterns, depending upon their technological and social organization and other cultural choices (Turnbull 1968:135-137; Yellen 1977:53). In India, a number of hunter-gatherers, such as the Chenchus (Furer-Haimendorf 1943) and the Birhors (Williams 1969), have dispersal and congregation patterns conditioned by economic factors. Until a few decades ago, the Paliyans used to disperse into small groups in the summer months due to scarcity of food resources (P. M. Gardner 1969:158, 1984:414). The mobility pattern observed among these contemporary hunter-gatherers, who have been influenced by their agropastoral neighbors, cannot be directly applied to the Mesolithic context. To determine the dispersion-aggregation pattern of Mesolithic hunter-gatherers, further detailed research including surface surveys of the area to the east of the upper Gundar Basin (east of longitude $77^{\circ} 50^{\prime}$ ) and collecting data on the seasonality of the sites is necessary.

\section{HUNTER-GATHERERS OF THE IRON AGE-EARLY HISTORIC PERIOD}

Gundar Basin has plenty of evidence for the Iron Age agropastoral settlements (for details, see Selvakumar 2000). The Iron Age began in the upper Gundar Basin before the middle of the first millennium B.C. (Selvakumar 2000; Soundararajan 1973). There is no evidence for the indigenous development of agropastoral groups in the Gundar Basin. The ceramic evidence from the Gundar Basin indicates that there was migration of agropastoral groups from the northern part of 
peninsular India. It is possible that these agropastoral groups, who practiced smallscale farming and cattle and sheep-goat pastoralism and had iron technology most probably upset the ecological equilibrium. The hunter-gatherers and agropastoral groups perhaps had to compete with each other for available resources. The number of Iron Age settlements appearing in the middle of the upper Gundar Basin, which only had hunter-gatherer settlements during the Mesolithic period, suggests the possible pressure. Though the pressure on the hunter-gatherers might not have been high during the initial stages of the Iron Age when the density of agropastoral settlements was less, in the Early Historic period it might have increased, as the number of agropastoral settlements increased considerably (Selvakumar 2000).

It is not known whether the relationship between the agropastoralists and hunter-gatherers was one involving conflict or cooperation. It is most likely that with the appearance of the agropastoral groups in the first millennium B.C., hunter-gatherers were gradually displaced from the core areas of the basin and driven into the peripheral territories. The reoccupation of the Mesolithic site at $\mathrm{S}$. Pappinayakkanpatti, which is in the middle of the basin, by the agropastoral groups, and the evidence of hunter-gatherer occupation at the rockshelters in Virappatti and E. Gopalapuram, which lie in the marginal areas of the basin and were largely uninhabited during the Mesolithic period, support this claim. Nevertheless, the evidence, such as beads, pottery, and domestic animal bones from the rockshelter sites, most probably points towards positive interactions between hunter-gatherers and agropastoral groups. The presence of querns and grinding stones in Kanavaypatti Period II and the absence of the same in Period I, can be taken to denote that hunter-gatherers acquired edible grains from the agropastoral groups. Some of the wild animal bones and lithic materials occurring in the agropastoral sites were also, probably, a consequence of such interactions. Similar interrelationships are mentioned in the early Tamil (Sangam) texts (Singaravelu 1969) and also take place even today among the Paliyans and the village settlers in this basin (P. M. Gardner 1972) as well as among other groups in different parts of India (Misra and Nagar 1997). Besides exploiting the forest and marginal areas for their own subsistence, hunter-gatherers perhaps also collected forest products, which were in demand among the agropastoral village communities. In this regard the proposition that a few of the hunter-gatherer groups of India have played a substantial role in the Early Historic trade and exchange in general and Indian Ocean trade (Indo-Roman) in particular, by supplying several forest products (Fox 1969; Gupta 1997; Morris 1983; Stiles 1993), deserves mention here.

\section{CONCLUSIONS}

This study has shown that microlithic sites occur in the interior southern Tamil Nadu in three different culture-chronological contexts. Many of the microlithic sites, especially the surface scatters, seem to be palimpsestic in nature, having both Mesolithic and Iron Age-Early Historic remains. The 109 microlithic sites discovered in the basin have been divided into three categories on the basis of their size and artifact density. The characteristics of various categories of sites and the artifact distribution pattern indicate that Mesolithic groups probably had a residential mobility pattern. It has been proposed that Mesolithic groups would have 
moved into the area east of the basin during the post-monsoon season and returned to the upper Gundar Basin in the dry season as an adaptation to the fluctuations in resource availability.

There is convincing evidence that the hunter-gatherers, who continued to exist in the Iron Age-Early Historic period, interacted with the agropastoral groups. The relationship between these two groups seems to have been one involving both conflict and cooperation; while some groups interacted with the agropastoral groups, others appear to have been gradually driven into marginal areas.

Questions related to the proposed mobility pattern of Mesolithic groups, the nature and dynamics of the interaction between hunter-gatherers and agropastoral groups during the Iron Age-Early Historic period, the mobility pattern of the hunter-gatherers during the post-Mesolithic phase, and other related issues have to be focused on by future investigations.

\section{ACKNOWLEDGMENTS}

An earlier version of the paper was presented at the 25th annual conference of the Indian Society for Prehistoric and Quaternary studies held at Sri Nagar (Garhwal), U. P., India. I would like to thank the University Grants Commission of India for financial assistance, Prof. K. Paddayya for his support, Dr. P. K. Thomas and his colleagues for identifying the animal bones, and Dr. Richa Jhaldiyal for her useful comments on the draft and her help in preparing the maps.

\section{NOTES}

1. Colonies of similar gastropods have been found in rockshelters and caves that have humid atmospheres in the Gundar Basin.

2. In Selvakumar 1996 and 1997, the complexities involved in the formation of the archaeological record were not taken into consideration, and as a result, all the surface scatters were treated as belonging to the Mesolithic.

3. Letter (dated 22 August 1995) from Dr. Sheela Kusumgar, Physical Research Laboratory, Ahmedabad, India.

4. Letter (dated 5 March 1997) from Dr. Sheela Kusumgar, Physical Research Laboratory, Ahmedabad, India.

5. The 23 lithic artifacts from the Early Historic levels in the test trench at S. Pappinayakkanpatti were included in the assemblages of Mesolithic hunter-gatherers in Selvakumar (1997) due to my oversight. They have been excluded here.

6. Though chronology of the sites in Categories 1 and 2 is uncertain, some of them most likely have both Mesolithic and Iron Age-Early Historic assemblages.

\section{REFERENCES CITED}

Aiyappan, A.

1944 Mesolithic artifacts from Sawyerpuram in Tinnevelly district, South India. Spolia Zeylanica 24(2): 145-154.

Allchin, B.

1977 Hunters, pastoralists and early agriculturalists in South Asia, in Hunters, Gatherers and First Farmers Beyond Europe-An Archaeological Survey: 127-144, ed. J.V.S. Megaw. Leicester: Leicester University Press.

Allchin, B., And F. R. Allchin

1974 The relationship of Neolithic and later settled communities with those of late stone age hunters and gatherers in Peninsular India, in Indian Society, Historical Beginnings Essays in Memory of D. D. Kosambi: 45-66, ed. R. S. Sharma. New Delhi: Peoples Publishing House.

1983 The Rise of Civilization in India and Pakistan. New Delhi: Select Book Service Syndicate. 
Ammerman, A. J.

1981 Surveys and Archaeological Research. Annual Review of Anthropology 10:63-88.

Atherton, J. H.

1983 Ethnoarchaeology in Africa. African Archaeological Review 1:75-104.

Bettinger, R. L.

1980 Explanatory/predictive models of hunter-gatherer adaptation, in Advances in Archaeological Method and Theory 3:189-255, ed. M. B. Schiffer. New York: Academic Press.

BINFORD, L. R.

1972 An Archaeological Perspective. New York: Seminar Press.

1980 Willow smoke and dogs' tails: Hunter-gatherer settlement systems and archaeological site formation. American Antiquity 45:4-20.

Bisson, M.

1990 Lithic reduction sequences as an aid to the analysis of late stone age quartz assemblages from the Luano Spring Chingola, Zambia. The African Archaeological Review 8:103-138.

BRANTINGHAM, P. J.

1998 Mobility, competition, and Plio-Pleistocene hominid foraging groups. Journal of Archaeological Method and Theory 5(1):57-98.

CENSUS OF INDiA

1969 Paliyans, in Census of India 1961. Ethnographic Notes on Scheduled Tribes, Vol. 9, pt. 5B(i) : 195-248. (Published in 1969.)

Chang, K. C., ED.

1968 Settlement Archaeology. Pao Alto: National Press Books.

Chang, K. C.

1972 Settlement Patterns in Archaeology. Addison Wesley Module in Anthropology No. 24.

Clark, J. D., AND M. R. Kleindienst

1974 The stone age cultural sequence: Terminology, typology and raw material, in Kalambo Falls, Prehistoric Site, Later Prehistoric Cultures, vol. 2:71-105, ed. J. D. Clark. Cambridge: Cambridge University Press.

DeCorse, Christopher R.

1989 Material aspects of Limba, Yalunka and Kuranko ethnicity: Archaeological research in northeastern Sierra Leone, in Archaeological Approaches to Cultural Identity: 125-138, ed. Stephen Shennan. London: Unwin Hyman.

Deraniyagala, S. U.

1992 The Prehistory of Sri Lanka: An Ecological Perspective. Colombo: Department of Archaeological Survey.

Dunnell, R. C., And W. S. Dancey

1983 The siteless survey: A regional scale data collection strategy, in Advances in Archaeological Method and Theory 6:266-288, ed. M. B. Schiffer. New York: Academic Press.

EISENBERG, J. F., AND M. LOCKHART

1972 An Ecological Reconnaissance of Wilpattu National Park, Ceylon. Smithsonian Contribution to Zoology 101. Washington D.C.: Smithsonian Institution Press.

FOLEY, R.

1981 Off-site archaeology: An alternative approach for the short sighted, in Patterns of the Past: Studies in Honour of David Clarke: 157-183, ed. I. Hodder, G. Isaac, and N. Hammond. Cambridge: Cambridge University Press.

Foote, R. B.

1883 On the geology of Madura and Tinnevelly districts. Memoirs of the Geological Survey of India 20(2): 1-103.

1916 The Foot Collection of Prehistoric and Protohistoric Antiquities: Notes on Their Ages and Distribution. Madras: Government Museum.

Fox, R. G.

1969 Professional primitives: Hunter-gatherers of nuclear South Asia. Man in India 49(2): 139160.

Furer-Haimendorf, C. von.

1943 The Chenchus: Jungle Folk of the Deccan. London: Macmillan. 
GARDNER, P. M.

1965 Ecology and social structure in refugee populations: The Paliyans of South India. Unpublished Ph.D. diss. University of Pennsylvania, Philadelphia, and Ann Arbor, Michigan: University Microfilms.

1966 Symmetric respect and memorate knowledge: The structure and ecology of individualistic culture. Southwestern Journal of Anthropology 22:389-415.

1969 Paliyan social structure, in Contributions to Anthropology: Band Societies: 153-171, ed. D. Damas. Proceedings of the Conference on Band Organization, Ottawa, August 30 to September 2, 1965. National Museum of Canada, Bulletin 228. Ottawa: The Queens Printer.

1972 The Paliyans, in Hunters and Gatherers Today: 404-450, ed. M. G. Bicchieri. Illinois: Wave Land.

1982 Ascribed austerity: A tribal path to purity. Man 17:462-469.

1984 Bicultural oscillation as a long-term adaptation to cultural frontiers: Cases and questions. Human Ecology 13:411-432.

1988 Pressures for Tamil propriety in Paliyan social organization, in Hunters and Gatherers, vol. 1: History, Evolution and Social Change: 91-106, ed. T. Ingold, D. Riches, and J. Woodburn. New York: Berg.

GARDNER, R.A.M.

1986 Quaternary coastal sediments and stratigraphy, southeast India. Man and Environment $10: 51-72$.

1995 Red dunes and Quaternary paleoenvironment in India and Sri Lanka, in Quaternary Environments and Geoarchaeology of India. Essays in Honour of Prof. S. N. Rajaguru: 391-404, ed. S. Wadia, R. Korisettar, and V. S. Kale. Bangalore: Geological Society of India Memoir No. 32.

GARDNER, R.A.M., AND H. MARTingell

1990 Microlithic sites and their palaeoenvironmental setting, southeast India: A reevaluation. Geoarchaeology $5: 1-13$.

Gaussen, H., P. Legris, and M. Viart

1964 International Map of Vegetation and of Environmental Conditions at 1/1,000,000: Notes on the sheet Cape Comarin. New Delhi: Indian Council of Agricultural Research.

Gupta, H. P.

1990 Sholas in the South Indian montane: Past, present and future. Palaeobotanist 38:394403.

Gupta, H. P., and K. Prasad

1985 The vegetational development during 30,000 years B.P. at Colgrain, Ottacamund, Nilgiris, S. India. Journal of Palynology 21:174.

Gupta, S.

1997 Roman Egypt to Peninsular India: Archaeological patterns of trade 1st century B.C. to 3rd century A.D. Ph.D. diss., University of Poona.

Hassan, F. A.

1987 Re-forming archaeology: A foreword to natural formation processes and the archaeological record, in Natural Formation Processes and the Archaeological Record: 1-9, ed. D. T. Nash and M. D. Petraglia. Oxford: BAR International Series 352.

HBG

1976 Know Your District: Madurai. Handbook. Calcutta: Geological Survey of India on the Occasion of $125^{\text {th }}$ Anniversary Celebrations (1851-1976). Calcutta.

Hivernel, F.

1986 Artifacts made of quartz, in La Cotte De St. Brelade 1961-78. Excavations by C.B.M. Mcburny: 315-324, ed. P. Callow and J. M. Cornford. Norwich: Geo Books.

Hooja, R.

1988 The Ahar Culture and Beyond: Settlements and Frontiers of Mesolithic and Early Agricultural Sites in Rajasthan. Oxford: BAR International Series 412.

Indian Archaeology: A Review

Volumes for 1957-1958, 1958-1959, and 1960-1961. New Delhi: Archaeological Survey of India. 
JACOBSON, J.

1970 Mesolithic contexts in the Vindyan hills of central India. Ph.D. diss., Columbia University.

Jacobson, J.

1975 Static sites and peripatetic peoples: Notes on the archaeology population mobility in eastern Malwa, in Pastoralists and Nomads in South Asia: 68-91, ed. L. S. Leshnik and G. D. Sontheimer. Wiesbaden: Otto Harrassowitz.

Joснім, M. A.

1976 Hunter-Gatherer Subsistence and Settlement. A Predictive Model. New York: Academic Press.

Kelly, R. L.

1983 Hunter-gatherer mobility strategies. Journal of Anthropological Research 39:277-306.

1992 Mobility/sedentism: Concepts, archaeological measures, and effects. Annual Review of Anthropology 21:43-66.

Kennedy, K.A.R., J. R. Lukacs, R. F. Pastor, T. L. Jonston, N. C. Lovell, J. N. Pal, B. E. Hemphill, AND C. B. Burrow

1992 Human Skeletal Remains from Mahadaha: A Gangetic Mesolithic Site. South Asia Occasional Papers and Theses No. 11. Ithaca: Cornell University.

KSHIRSAGAR, A.

1993 Role of fluorine in the chronometric dating of Indian stone age cultures. Man and Environment $18(2): 23-32$.

MisRa, V. N.

1965 Mesolithic phase in India, in Indian Prehistory: 577-585, ed. V. N. Misra and M. S. Mate. Poona: Deccan College Post-Graduate and Research Institute Building Centenary and Silver Jubilee Series 32.

1973 Bagor: A Mesolithic settlement in northwest India. World Archaeology 5(1):92-110.

1976 Evidence of culture contact between terminal stone age hunter-gatherers and contemporary farmers, in Archaeological Congress and Seminar 1972: 115-121, ed. U. V. Singh. Kurukshetra: B. N. Chakravarty University.

1989 Stone age India: An ecological perspective. Man and Environment 14:17-64.

Misra, V. N., and Malti Nagar

1997 From tribe to caste: An ethnoarchaeological perspective, in From Tribe to Caste: 136-166, ed. D. Nathan. Shimla: Indian Institute of Advanced Study.

Mohanty, P.

1993 Mesolithic hunter-gatherers of Keonjhar district, Orissa, India. Asian Perspectives 32(1): 85-109.

Murdock, R.

1967 Ethnographic atlas: A summary. Ethnology 6:109-236.

Murty, M.L.K.

1989 Pre-Iron Age agricultural settlements in South India: An ecological perspective. Man and Environment 14(1): 65-81.

O'Connell, J. F.

1995 Ethnoarchaeology needs a general theory of behavior. Journal of Archaeological Research 3(3) : 205-255.

OTA, S. B.

1986 Mesolithic culture of the Phulbani district, Orissa with special reference to the heavy tool component. Bulletin of the Deccan College Post Graduate and Research Institute 45: 79-87.

PADDAYYA, K.

1982 The Acheulian Culture of the Hunsgi Valley, Peninsular India: A Settlement System Perspective. Poona: Deccan College Post Graduate Research Institute.

Possehl, G. L., COMP.

1994 Radiometric Dates for South Asian Archaeology. An Occasional Publication of the South Asia Section. The University of Pennsylvania Museum, Philadelphia, Pennsylvania.

RAJAN, K.

1994 Archaeology of Tamil Nadu: Kongu Country. New Delhi: Book India Publishing Co. 
Ramachandran, K. K., P. Vijayakumar, and P. S. Easa

1986 Ecology of larger mammals of Periyar Wild Life Sanctuary. Journal of Bombay Natural History Society 83(3) : 505-524.

RAMAN, K. V.

1970 Distribution pattern of cultural traits in the pre- and protohistoric times of Madurai region. Aaraichi 1:499-509.

Roberts, N., AND H. E. WRIGHT Jr.

1993 Vegetational, lake-level, and climatic history of the Near East and southwest Asia, in Global Climates since the Last Glacial Maximum: 194-220, ed. H. E. Wright Jr., J. E. Kutzbach, T. Webb III, W. F. Ruddiman, F. A. Street-Perrott, and P. J. Bartlein. Minneapolis: University of Minnesota Press.

Rossingol, J., AND. L. WANDSNider, EDS.

1992 Space, Time and Archaeological Landscapes. New York: Plenum Press.

SANKALIA, H. D.

1964 Stone Age Tools: Their Techniques, Names and Probable Functions. Deccan College Building Centenary and Silver Jubilee Series No. 1. Poona: Deccan College Post Graduate and Research Institute.

Schiffer, M. B., A. P. Sullivan, and T. C. Klinger

1978 The design of archaeological surveys. World Archaeology 10:1-28.

Selvakumar, V.

1996 Archaeological investigations in the upper Gundar Basin. Man and Environment 22(2):2742.

1997 Investigations into the prehistoric and protohistoric cultures of the upper Gundar Basin. Ph.D. diss., University of Poona.

2000 Investigations into the Iron Age-Early Historic cultures of the upper Gundar Basin, Madurai district, Tamil Nadu, India. South Asian Studies 16:119-132.

2001 Culture and chronology of lithic industries from southern Tamil Nadu, in Kaveri: Studies in Epigraphy, Archaeology and History-Professor Y. Subbarayalu Felicitation Volume: 256266, ed. S. Rajagopal. Chennai: Pannpattu Veliyiittakam.

SHennan, STEPHEN

1989 Introduction: Archaeological approaches to cultural identity, in Archaeological Approaches to Cultural Identity: 1-32, ed. Stephen Shennan. London: Unwin Hyman.

Singaravelu, S.

1969 Social Life of Tamils. The Classical Period. Kuala Lumpur: University of Malaysia.

Singh, G.R.J. WASSON, and O. P. Agrawal

1990 Vegetational and seasonal climatic changes since the last full glacial in the Thar Desert, northwestern India. Review of Palaeobotany and Palynology 64:351-358.

Stiles, D.

1993 Hunter-gatherer trade in wild forest products in the early centuries with the Port of Broach India. Asian Perspectives 32(2): 153-167.

Thompson, Webb III, W. F. Ruddiman, F. A. Street-Perrott, V. Markgraf, J. E. Kutzbach, P. J. Bartlein, and W. L. Prell

1993 Climatic changes during the past 18,000 years: Regional synthesis, mechanisms and causes, in Global Climates since the Last Glacial Maximum: 514-535, ed. H. E. Wright Jr., J. E. Kutzbach, T. Webb III, W. F. Ruddiman, F. A. Street-Perrott, and P. J. Bartlein. Minneapolis: University of Minnesota Press.

Thurston, E., and RANGaChari, K.

1909 Castes and Tribes of Southern India, vol. 5. Madras: Government Press.

TRIGGER, B.

1978 Times and Traditions: Essays in Archaeological Interpretation. New York: Columbia University Press.

Turnbull, C. M.

1968 The importance of flux in two hunting societies, in Man The Hunter: 132-137, ed. R. B. Lee and I. DeVore. Chicago: Aldine.

VAN Campo, E.

1986 Monsoon fluctuations in two 20,000-yr B.P. oxygen-isotope/pollen records off southwest India. Quaternary Research 26:376-388. 
VedACHALAM, V.

1985 Madurai Mavatta Paguthikalil Nunkarkala Kandupidipugal. Paper presented during the seminar conducted by the Department of Archaeology, Tamil Nadu.

WASSON, R. J.

1995 The Asian monsoon during the late Quaternary: A test of orbital forcing and palaeoanalogue forecasting, in Quaternary Environments and Geoarchaeology of India. Essays in Honour of Prof. S. N. Rajaguru: 22-35, ed. S. Wadia, R. Korisettar, and V. S. Kale. Bangalore: Geological Society of India Memoir No. 32.

Wasson, R. J., G. I. Smith, and D. P. Agrawal

1984 Late Quaternary sediment, mineral and infrared geochemical history of Didwana Lake, Thar Desert, India. Palaeogeography, Palaeoclimatology, Paleoecology 46:345-372.

Wheeler, R.E.M., A. Ghosh, and Krishna Deva

1946 Arikamedu: An Indo-Roman trading-station on the east coast of India. Ancient India $2: 17-124$.

WILEY, G. R.

1953 Prehistoric Settlement Patterns in the Viru Valley, Peru. Bureau of American Ethnology, Bulletin 155. Washington, D.C.: Smithsonian Institution.

Williams, B. J.

1969 The Birhor of Hazaribagh, in Contributions to Anthropology: Band Societies: 142-152, ed. D. Damas. Proceedings of the Conference on Band Organization, Ottawa, August 30 to September 2, 1965. National Museum of Canada, Bulletin 228. Ottawa: The Queens Printer.

Yellen, J. E.

1977 Archaeological Approaches to the Present. Models for Reconstructing the Past. New York: Academic Press.

Zeuner, F. E., AND B. Allchin

1956 The microlithic sites of Tinnevelly district, Madras State. Ancient India 12:4-20.

Zvelebil, K.

1975 Pastoralism as reflected in the classical theory of landscapes, in Pastoralists and Nomads in South Asia: 30-39, ed. L. S. Leshnik and G. D. Sontheimer. Wiesbaden: Otto Harrassowitz.

\section{ABSTRACT}

Archaeological investigations undertaken in the upper Gundar Basin (Madurai district, Tamil Nadu, India) between 1991 and 1996 have yielded evidence for the Mesolithic and Iron Age-Early Historic periods. The research has revealed that microlith-using hunter-gatherers continued to exist during the Iron Age and Early Historic periods, and interacted with agropastoral groups. This paper discusses the settlement system of Mesolithic hunter-gatherers and interactions between the hunter-gatherers and the agropastoral groups of the Iron Age-Early Historic period. Keywords: Madurai, Tamil Nadu, India, South Asia, microliths, Mesolithic, Iron Age, Early Historic, hunter-gatherers. 